Article

\title{
Evaluation of Liposome-Loaded Microbubbles as a Theranostic Tool in a Murine Collagen-Induced Arthritis Model
}

\author{
Joke Deprez ${ }^{1,2} \mathbb{D}$, Silke Roovers ${ }^{1,2}$, Guillaume Lajoinie ${ }^{3}$, Heleen Dewitte ${ }^{1,2}$, Tine Decruy ${ }^{4}$, Julie Coudenys ${ }^{4}$, \\ Benedicte Descamps ${ }^{5}$ (D) Christian Vanhove ${ }^{5}$ (D), Michel Versluis ${ }^{3}\left(\mathbb{D}\right.$, Dirk Elewaut ${ }^{4}$, Peggy Jacques ${ }^{4}$, \\ Stefaan C. De Smedt ${ }^{1,2, *, t}$ and Ine Lentacker ${ }^{1,2,+}$
}

Citation: Deprez, J.; Roovers, S.; Lajoinie, G.; Dewitte, H.; Decruy, T.;

Coudenys, J.; Descamps, B.; Vanhove,

C.; Versluis, M.; Elewaut, D.; et al. Evaluation of Liposome-Loaded Microbubbles as a Theranostic Tool in a Murine Collagen-Induced Arthritis Model. Sci. Pharm. 2022, 90, 17. https://doi.org/10.3390/ scipharm 90010017

Academic Editor: Natasa Skalko-Basnet

Received: 16 December 2021 Accepted: 23 February 2022 Published: 28 February 2022

Publisher's Note: MDPI stays neutral with regard to jurisdictional claims in published maps and institutional affiliations.

Copyright: (C) 2022 by the authors. Licensee MDPI, Basel, Switzerland. This article is an open access article distributed under the terms and conditions of the Creative Commons Attribution (CC BY) license (https:// creativecommons.org/licenses/by/ $4.0 /)$.
1 Laboratory of General Biochemistry and Physical Pharmacy, Ghent Research Group on Nanomedicine, Ghent University, 9000 Ghent, Belgium; joke.deprez@ugent.be (J.D.); silke.roovers@ugent.be (S.R.); heleen.dewitte@ugent.be (H.D.); ine.lentacker@ugent.be (I.L.)

2 Cancer Research Institute Ghent (CRIG), 9000 Ghent, Belgium

3 Physics of Fluids Group, MESA+ Institute for Nanotechnology and Technical Medical (TechMed) Center, University of Twente, P.O. Box 217, 7500 AE Enschede, The Netherlands; g.p.r.lajoinie@utwente.nl (G.L.); m.versluis@utwente.nl (M.V.)

4 Unit Molecular Immunology and Inflammation, VIB Centre for Inflammation Research, Ghent University and Department of Rheumatology, Ghent University Hospital, 9000 Ghent, Belgium; tine.decruy@ugent.be (T.D.) julie.coudenys@ugent.be (J.C.); dirk.elewaut@ugent.be (D.E.); peggy.jacques@ugent.be (P.J.)

5 Infinity Lab, Institute Biomedical Technology, Medical Imaging and Signal Processing, Ghent University, 9000 Ghent, Belgium; benedicte.descamps@ugent.be (B.D.); christian.vanhove@ugent.be (C.V.)

* Correspondence: stefaan.desmedt@ugent.be

$\dagger$ These authors contributed equally to this work.

\begin{abstract}
Rheumatoid arthritis (RA) is an autoimmune disease characterized by severe inflammation of the synovial tissue. Here, we assess the feasibility of liposome-loaded microbubbles as theranostic agents in a murine arthritis model. First, contrast-enhanced ultrasound (CEUS) was used to quantify neovascularization in this model since CEUS is well-established for RA diagnosis in humans. Next, the potential of liposome-loaded microbubbles and ultrasound (US) to selectively enhance liposome delivery to the synovium was evaluated with in vivo fluorescence imaging. This procedure is made very challenging by the presence of hard joints and by the limited lifetime of the microbubbles. The inflamed knee joints were exposed to therapeutic US after intravenous injection of liposomeloaded microbubbles. Loaded microbubbles were found to be quickly captured by the liver. This resulted in fast clearance of attached liposomes while free and long-circulating liposomes were able to accumulate over time in the inflamed joints. Our observations show that murine arthritis models are not well-suited for evaluating the potential of microbubble-mediated drug delivery in joints given: (i) restricted microbubble passage in murine synovial vasculature and (ii) limited control over the exact ultrasound conditions in situ given the much shorter length scale of the murine joints as compared to the therapeutic wavelength.
\end{abstract}

Keywords: microbubbles; CEUS; rheumatoid arthritis; CIA; theranostics; angiogenesis; sonoprinting; liposomes; EPR

\section{Introduction}

Rheumatoid arthritis (RA) is an auto-immune disease characterized by persistent joint inflammation resulting in irreversible cartilage degradation and bone erosion when left untreated [1,2]. About $0.5-1 \%$ of the population in developed countries is affected by the disease, mostly middle-aged patients. Incidence and prevalence rates are twice as high in women than in men $[1,3,4]$. Unfortunately, the real cause of the pathology has not yet been fully elucidated $[3,5]$. The synovial lining expands dramatically in affected joints as a result of massive immune cell infiltration [2]. During the inflammatory process, uncontrolled neovascularization occurs to provide a constant transport of oxygen and nutrients to the 
hypertrophic site of inflammation. Moreover, this neovasculature facilitates the transport of leukocytes to the synovial lining, leading to tissue remodelling and additional damage [5,6]. Imaging techniques are routinely used to quantify disease progression and to detect swelling, inflammation, and destruction of cartilage and bone structure [1]. While radiography is frequently used as a research tool, it is uncommon in clinical practice as this technique is only capable of visualizing irreversible damage at the level of the cartilage and the bone itself [7]. Other imaging techniques include computed tomography (CT), magnetic resonance imaging (MRI), and ultrasound (US). These modalities are becoming increasingly popular as they allow the visualization of both irreversible and reversible structural changes. Thus, they offer a better understanding of the disease status and allow to closely monitor disease progression $[1,2,8]$. Ultrasound, in particular, is a safe, non-radioactive, non-invasive, fast, and cost-effective imaging technique with minimal side effects $[9,10]$. Ultrasound imaging allows to visualize cartilage and soft tissue changes such as joint swelling and synovial thickening as well as neovascularization [2,7]. Therefore, ultrasound imaging has been used intensively to detect and monitor disease progression of RA in the clinic [10-14]. Functional ultrasound imaging modalities such as colour Doppler, power Doppler, or contrast-enhanced ultrasound (CEUS) have been reported to be particularly useful for RA detection as they allow better visualisation and even quantification of the blood flow [9,12,14-20]. During CEUS, ultrasound microbubble contrast agents [20-22] are injected intravenously to improve the visualization of organ perfusion and blood vessels delineations. Microbubbles consist of a hydrophobic gas core stabilized by a shell composed of lipids, proteins, or polymers [23-31]. The compressibility of the gas core allows them to respond to the different pressure phases of ultrasound [32,33] by continuous contraction and expansion, termed microbubble cavitation. Microbubble vibration leads to ultrasound emission that can then be received by the imaging transducer [34]. Due to their rather large size $(1-10 \mu \mathrm{m})$ [35], microbubbles are limited to the blood circulation and are as such ideal blood pool agents for imaging the heart [36,37], the liver [38,39] or the kidneys [40-42]. A range of microbubble contrast agents, including Definity ${ }^{\mathrm{TM}}$, Optison ${ }^{\mathrm{TM}}$, Sonazoid ${ }^{\mathrm{TM}}$, and Sonovue $^{\mathrm{TM}}$ are clinically approved and commercially available $[28,35,43,44]$.

Apart from their role as contrast agents, microbubbles have been extensively studied as drug delivery agents. It has been demonstrated that cavitating microbubbles are able to temporarily permeabilize cell membranes, a process called sonoporation [45]. The potential of microbubbles has been corroborated in many preclinical models in vivo [46-58], where it has been shown that microbubble cavitation can stimulate drug delivery across biological barriers such as the endothelium, the blood-brain barrier, tumor tissue, etc. [59-64]. However, enhanced drug uptake in these studies has been limited mainly to small molecular weight drugs as their smaller size allows them to passively diffuse through cell membrane pores or endothelial gaps. In the case of nanomedicines, such as liposomes, our group and others have demonstrated that microbubble loading might be more advantageous to actively deposit drug-loaded liposomes onto cellular membranes or tissues [65-69]. High-speed imaging experiments have revealed that during microbubble cavitation, lipid microbubbles can shed their lipid shell together with the attached liposomes. They are then deposited onto the cell membrane in the wake of the translating microbubble gas core, a process we termed sonoprinting $[67,70]$. Given promising preliminary results on the use of ultrasound and CEUS for RA diagnosis in humans [10-14,71-73], there is tremendous interest in using the same bubbles for local drug delivery purposes. Here, we first investigate whether CEUS can be a useful tool to quantify neovascularisation in arthritic mice. Subsequently, we quantify the ultrasound-mediated drug deposition from liposome-loaded microbubbles at the inflamed synovium. We show that the liposome-loaded microbubbles demonstrate a much lower drug delivery efficiency than free uncoupled liposomes. Importantly, the use of larger preclinical animals will be crucial to accurately evaluate the true potential of liposome-loaded microbubbles for RA therapy. 


\section{Results}

\subsection{Physicochemical Characterization of Microbubbles}

Lipid microbubbles were prepared via high-frequency shaking of a DPPC:DSPE-PEGbiotin $_{3400}$ lipid solution in a 85:15 molar ratio with perfluorobutane $\left(\mathrm{C}_{4} \mathrm{~F}_{10}\right)$ gas. To produce liposome-loaded microbubbles, biotinylated liposomes (Supplementary Figure S1) and microbubbles were first prepared separately and subsequently coupled via biotin-avidinbiotin bridging $[67,70]$. The fluorescent liposome loading of the microbubbles was analysed by flow cytometry using the gating strategy explained in Supplementary Figure S2. In the current study, we made liposomes composed of DSPC, cholesterol, and DSPE-PEG $3400^{-}$ biotin in a 45:40:15 molar ratio to allow efficient liposome attachment to the microbubble surface as previously described by our group $[66,67,70,74]$. Although we observed some non-specific interaction between liposomes and microbubbles in the absence of avidin, avidin-biotin coupling was required to allow efficient liposome loading of the microbubbles (Supplementary Figure S3). The size and polydispersity index (PDI) of the liposomes are summarized in Supplementary Figure S1. Subsequently, an excess of biotinylated liposomes was added to the microbubble formulation in a 6600 liposomes/MB ratio to reach the final microbubble suspension for injection. We demonstrated before that the microbubble size distribution was not drastically affected after liposome loading [67] (Figure 1A). Overall, the microbubble size distribution is similar to Definity ${ }^{\mathrm{TM}}$ [75], a commercially available and clinically used lipid microbubbles. By including a fluorescent lipophilic dye in the liposome formulation (DiD), we were able to visualize liposome coupling to the microbubbles. Liposome coupling led to a homogenous distribution of fluorescently labelled liposomes onto the microbubble shell, as visualized via confocal microscopy (Figure 1B) and was consistent with earlier reports from our group [67,70]. Secondly, the stability of the liposome-microbubble coupling in biological media was investigated in full serum. This was done to verify if liposomes would stay attached to the microbubbles after injection. Three different batches of liposome-loaded microbubbles (blue, green, and red) were diluted in HEPES (full line) or full serum (dotted line) and the liposomal load of the different microbubble batches was quantified with flow cytometry (Figure 1C). The liposome-loading was conserved in serum as both the histogram shape (dotted line) as well as the Mean Fluorescence Intensity (MFI) (i.e., peak location) of the bubbles completely overlap with the histograms of HEPES-diluted (full line) liposomeloaded microbubbles.

\subsection{Preclinical CEUS Imaging of the Synovial Vasculature in Healthy and CIA Mice}

RA is a chronic inflammatory disease characterized by synovial inflammation and neoangiogenesis. The latter is known to correlate with disease severity and aggressiveness of the synovitis [12,76] and therefore quantitative detection of synovial neovascularization via CEUS is clinically established to estimate disease progression [10]. Despite the clinical use of CEUS to quantify RA-induced neovascularisation, there are no reports on the applicability in preclinical mouse models of RA, e.g., collagen-induced arthritis (CIA) model. This model allows studying chronic inflammation in a full-blown inflammation model that follows a similar disease progression as human RA [77-80], including neovascularisation [77,81-84]. We, therefore, investigated whether we were able to detect neo-angiogenesis in CIA-induced mice by CEUS imaging. Figure 2A illustrates the timeline of this experiment. The knees of male DBA/1 mice were subjected to CEUS imaging before and after CIA induction. Mice were visually scored based on swelling and erythema of the paw, including the digits, which resulted in a CIA score of 0 (no inflammation) to 4 (severe inflammation with deformations) (Supplementary Figure S4). To optimally visualize the synovial cavity using CEUS, the knee joint was placed in a ninety-degree angle (Figure 2B) providing a clear view of the synovial cavity (Figure 2C) $[10,19,85]$. Mice were intravenously injected with plain, unloaded lipid microbubbles and the VEVO small animal imager equipped with the MS-250 probe (13-24 MHz) was used to perform CEUS imaging of the synovial cavity. We quantified microbubble influx using a nonlinear contrast imaging mode by looking 
specifically at the level of increase of the microbubble-related contrast signal compared to the basal contrast signal of the synovium ('mean increase in contrast power') as well as the time between microbubble injection and maximal contrast ('time to peak') (Supplementary Figure S5). After CEUS, mice were immunized, followed by a boost immunization 21 days later [78] (Figure 2A). In the second part of the CEUS study, the inflamed knees (score 3) were imaged with CEUS, following the same procedure as the first CEUS experiment before CIA induction. Figure 2D displays the 'mean increase in contrast power' and 'time to peak' measured with CEUS in healthy (grey bars) and inflamed knees (black bars). The inflammation caused no significant differences in the total microbubble influx (contrast mean power) or the onset of microbubble influx (time to peak) between healthy or inflamed knees. Nonetheless, a clear microbubble influx in the synovium does appear within seconds after microbubble injection (Supplementary Figure S5), which allows to further investigate the therapeutic effect of loaded bubbles in this mouse model.
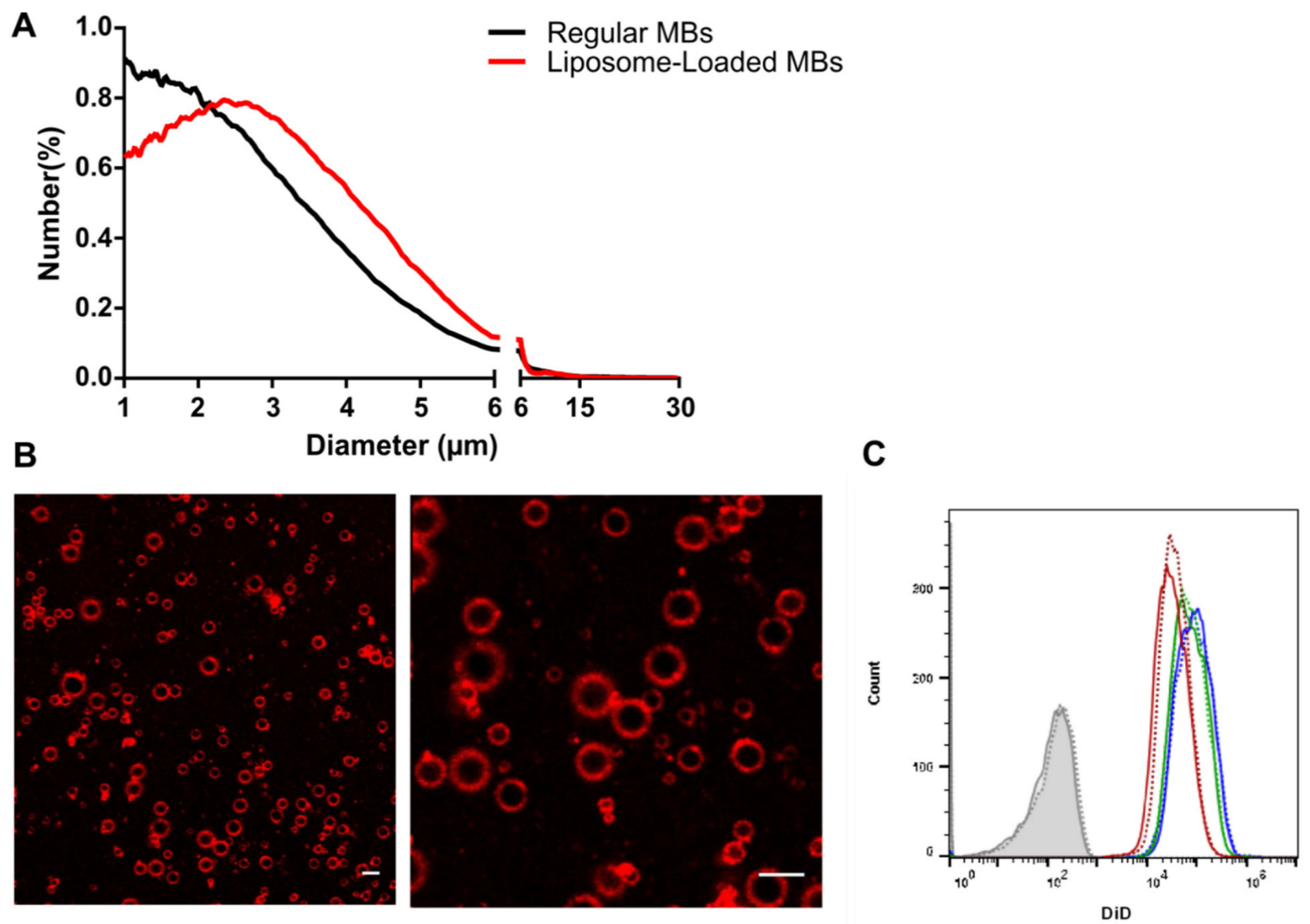

Figure 1. Characterization of liposome-loaded microbubbles. (A) Size distribution of biotinylated lipid microbubbles with (red line) and without (black line) liposomes attached, displayed in number\% of the total microbubble population. (B) Confocal images of fluorescently labelled liposome-loaded microbubbles. Red fluorescence indicates the presence of DiD labelled liposomes. Scale bar equals $5 \mu \mathrm{m}$ (C) Flow cytometry histograms of liposome-loaded microbubbles diluted in HEPES (full line) or full serum (dotted line). Coloured histograms (green, blue, red) represent different batches of liposome-loaded microbubbles. Grey histograms represent unloaded microbubbles as a reference. 


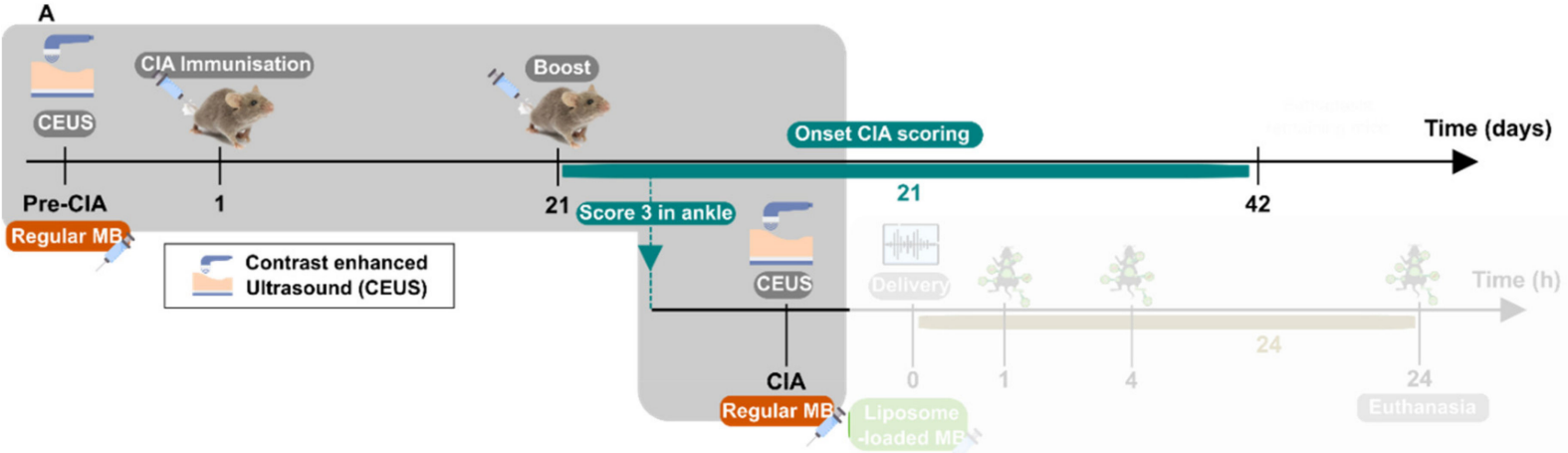

B Animal and knee positioning

C
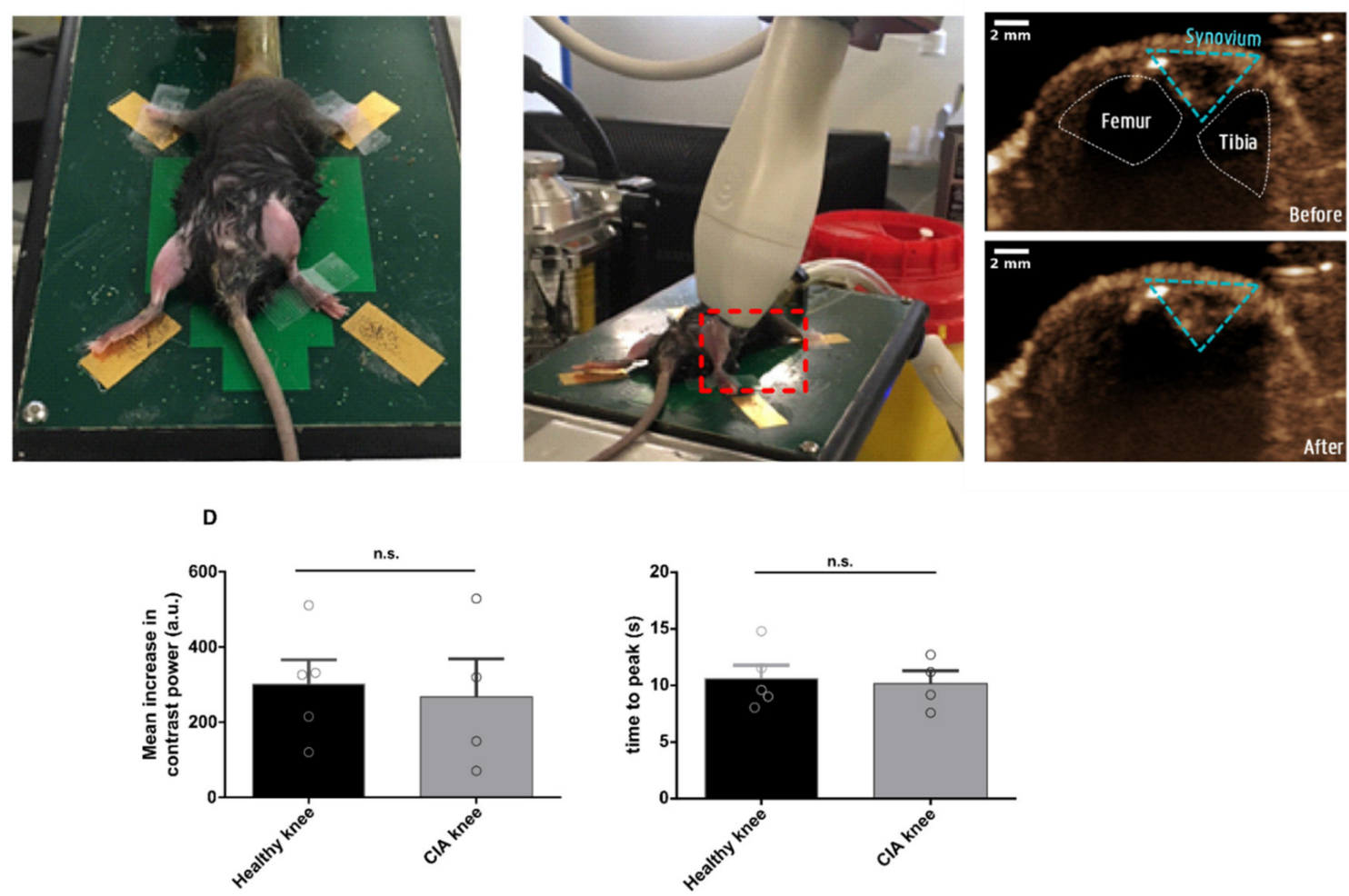

Figure 2. CEUS imaging of inflamed synovium in healthy and CIA mice. (A) Timeline of the experimental study and visualization of the imaging experiment (grey box): CEUS imaging of the knee joints of healthy mice ('pre-CIA') was performed to quantify microbubble influx before CIA induction. Subsequently, CIA was induced by intradermal injection of a collagen emulsion (day 1) or booster injection (day 21). Only mice that reached a visual CIA score of 3 in at least one ankle were included in the follow-up study. The knee synovium of mice with a visual score of 3 in the ankle joint was imaged with CEUS (grey). (B) Example of the experimental set-up for ultrasound imaging and treatment in C57BL/6, the mouse was placed supine and the knee was tilted and fixed at a ninety-degree angle to allow ultrasound imaging of the synovial cavity. The ultrasound probe was positioned perpendicular to the tilted knee (red square) in line with the position of the femur. (C) CEUS image before (upper image) and $10 \mathrm{~s}$ after microbubble injection (lower image) of the knee synovium (dotted line) in DBA/1 mice. (D) Quantitative analysis of the CEUS images of healthy (grey bars, $n=5$ ) and inflamed knees (black bars, $n=4$ ) of DBA:1 mice, each dot represents one mouse: mean increase in contrast power (left graph) and time to peak (right graph), compared via a paired $t$-test. 


\subsection{Can Ultrasound Exposure of Liposome-Loaded Microbubbles Enhance Liposome Delivery to Arthritic Joints?}

Figure $3 \mathrm{~A}$ shows a timing diagram of the drug delivery experiment, which is performed on the same CIA mice that were included in the second CEUS imaging experiment. We placed a $1 \mathrm{MHz}$ therapeutic ultrasound transducer on the knee joint under the same position as the imaging transducer (Figure 2B). Subsequently, CIA mice were intravenously injected with microbubbles loaded with fluorescently labelled (DiR) liposomes [86,87] where after therapeutic ultrasound pulses $\left(1 \mathrm{MHz}, 2 \mathrm{~W} / \mathrm{cm}^{2}\right.$ or $\left.4 \mathrm{~W} / \mathrm{cm}^{2}\right)$ were sent for $30 \mathrm{~s}$ to induce microbubble cavitation. We have previously demonstrated that these US parameters induce efficient liposome release and disposition from the microbubbles, named sonoprinting, on cell cultures as well as in complex 3D tumor spheroid models in vitro $[66,67,74,88]$. The visual CIA scores of the front paws and hind limbs is displayed next to each limb in Figure 3. Immediately after therapeutic ultrasound treatment, CEUS imaging of the synovium was repeated (without new injection of contrast) to confirm that circulating microbubbles were either destroyed or removed from circulation. No remaining microbubbles could then be detected in the synovium. Subsequently, we performed whole-body fluorescence imaging to determine the location of the fluorescently labelled liposomes up to $24 \mathrm{~h}$ after therapeutic ultrasound exposure as they are characterized by blood circulation times that exceed $48 \mathrm{~h}$ post intravenous injection [89-91]. Figure 3 shows representative fluorescent whole-body images of mice that were injected with liposomeloaded microbubbles and subsequently treated with therapeutic ultrasound (Figure 3B,C) or not treated with ultrasound (Figure 3D). The ultrasound-exposed knee joint is indicated by a blue arrow.

One hour after ultrasound exposure we could not detect more fluorescence in the ultrasound-exposed joints (indicated by the blue arrows in Figure 3B,C) as compared to the untreated knee joints in the same mouse. The 'throat-neck' area (blue circles) was used to estimate the blood circulation time of the liposomes and indicates that many fluorescent liposomes are still in circulation after the ultrasound treatment. During followup, we noticed that the fluorescence intensity in the inflamed paws increased over time and was clearly enhanced $24 \mathrm{~h}$ after microbubble injection in both the ultrasound-treated (Figure 3B,C) as well as the non-treated control (Figure 3D). Although we could detect a higher fluorescence intensity in the ultrasound-treated knees at this later time point, it was difficult to compare this to the fluorescence from the untreated knee in the same mouse, as the CIA scores differed. Interestingly, we noticed that all mice displayed in Figure 3 had one (untreated) front paw with a CIA score of 3 where we measured the same high fluorescence intensities independent of the ultrasound power (Figure 3B-D). The fluorescence intensity of these score 3 front paws was comparable to the fluorescence intensity detected in the knees and ankles with a similar CIA score (Figure 3B,C). These findings show that the long-term liposome accumulation was not induced by the ultrasound but rather correlates with the degree of inflammation. Figure $3 \mathrm{~F}$ illustrates the increase in liposomal fluorescence $24 \mathrm{~h}$ after injection of the liposome-loaded microbubbles in US-treated and no-US treated mice respectively. This relative quantification clearly shows that there was a similar increase in liposomal accumulation was observed in CIA score 3 joints, regardless of ultrasound treatment. The absolute radiance values of the displayed CIA score 3 joints can be retrieved in Supplementary Figure S6. 


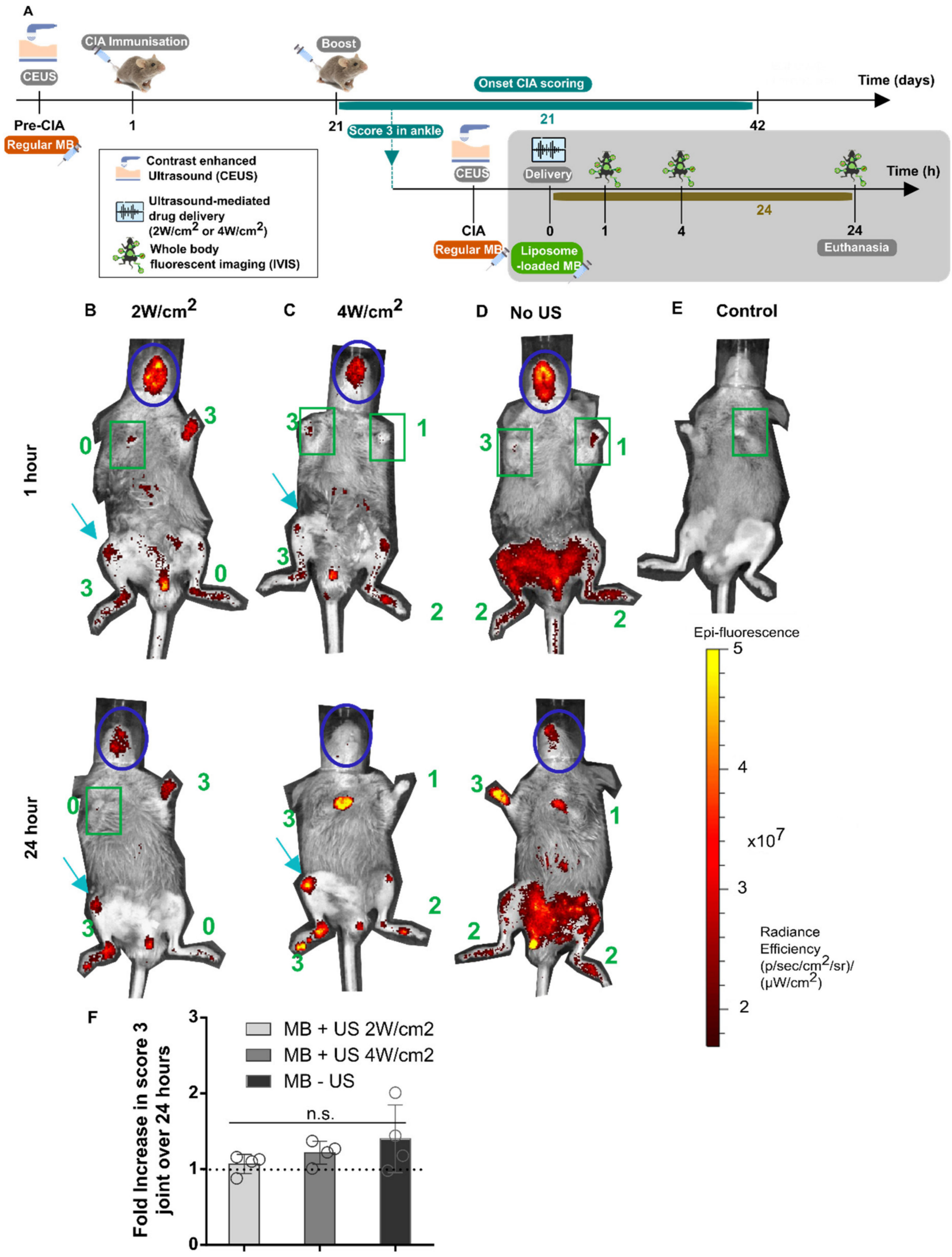

Figure 3. Whole-body fluorescence images to illustrate the bio-distribution of fluorescently labelled liposomes. (A) Timeline of the whole experimental study. The therapeutic study is indicated by the grey box: after the second CEUS imaging, mice were i.v. injected with liposome-loaded microbubbles and the knee of mice with a visual score 3 in the ankle joints were exposed to a therapeutic ultrasound 
pulse ( 2 or $4 \mathrm{~W} / \mathrm{cm}^{2}$ ) (grey). Subsequently, whole-body imaging was performed at 1, 4, and $24 \mathrm{~h}$. (B-D) Whole-body images of the accumulation of DiR liposomes in inflamed joints at 1 and $24 \mathrm{~h}$ after i.v. injection of liposome-loaded microbubbles and therapeutic ultrasound treatment. Mice were treated with $2 \mathrm{~W} / \mathrm{cm}^{2}(\mathbf{B}), 4 \mathrm{~W} / \mathrm{cm}^{2}$ (C) therapeutic $1 \mathrm{MHz}$ ultrasound for $30 \mathrm{~s}$ exposure time or not treated with ultrasound (D). To illustrate the background fluorescence, a control mouse that was not injected with liposome-loaded microbubbles is depicted in (E). The ultrasound-treated knee of each mouse is indicated by a blue arrow. The visual score of the front paws and ankles of the mice is displayed next to each limb. Green squares are added as a visual aid to locate the front paw. The 'throat-neck' area to estimate the liposomes that remain in circulation is indicated by a blue circle. $n=4$ replicates for each ultrasound condition. (F) Overview of fluorescence increase over $24 \mathrm{~h}$ after injection of the liposome-loaded microbubbles in CIA score 3 US-treated knees either exposed to a therapeutic ultrasound pulse of 2 or $4 \mathrm{~W} / \mathrm{cm}^{2}$ (each dot represents a treated knee), and score 3 joints (including knees, ankles, and front paws (each dot represents score 3 joint) in mice that were not exposed to ultrasound. Different treatment groups were compared via one-way ANOVA, with Tukey's correction for multiple testing.

Earlier studies have shown that long-circulating, PEGylated liposomes can passively accumulate over time in the inflamed synovium, which has been attributed to the enhanced permeation and retention effect (EPR) [92,93]. Due to the high liposome to bubble ratio and the lack of an extra washing step after microbubble loading a high fraction of free, uncoupled liposomes was co-injected with the liposome-loaded microbubbles [94,95]. As we could still detect a high number of liposomes in circulation, this suggests that the higher fluorescence intensities might be the result of passively accumulated rather than actively deposited liposomes. Therefore, we further optimized our liposome-loaded microbubbles to reduce the fraction of free, uncoupled liposomes in the bubble suspension. More specifically, we balanced the liposome/microbubble ratio in order to minimize the number of free liposomes, while maintaining a high liposome load of the bubbles (Figure 4). We varied the volume of DiD-labelled, biotinylated liposomes (from 1000 to 10,000 liposomes per MB) that was added to the avidin-activated microbubbles suspension and compared the Mean Fluorescence Intensity (MFI) of the liposome-loaded microbubbles by flow cytometry (Supplementary Figure S7). Our original liposome-loaded microbubble formulation was prepared by adding 6600 liposomes per MB (blue bars), but we could significantly lower the liposome/bubble ratio with only a minor impact on the liposomal load of the microbubbles (Figure 4). Based on these results, we decided to continue with a ratio of 1000 liposomes per MB (orange bar). This ratio resulted in a reduced microbubble loading of around $63.1 \%$ when compared to the original one (blue bar), which guaranteed a minimal number of free liposomes with a minimal impact on the liposomal load of the microbubbles.

The experiment was repeated using this optimized microbubble formulation in a new set of mice. In these experiments, CIA mice were injected with either the optimized microbubble formulation (Figure 5A,B) or exactly the same dose of free liposomes ('free liposomes') to allow direct comparison between liposome-loaded microbubbles and freelycirculating liposomes in terms of synovial targeting and retention (Figure 5C). The knee (CIA score 3 ) of the microbubble injected mice were treated with $2 \mathrm{~W} / \mathrm{cm}^{2}$ or $4 \mathrm{~W} / \mathrm{cm}^{2}$ (respectively Figure 5A,B blue arrows) ultrasound for $30 \mathrm{~s}$, in similarity to the previous experiment. We could not retrieve any liposome signal from the ultrasound-treated knees immediately after the ultrasound treatment or at later time points. Instead, all liposome signal was retrieved in the liver and quickly metabolized. This was also the case for untreated knees in those mice that had a similar CIA score. Figure 5D confirms that there was no increase in liposome signal in any score 3 joints over $24 \mathrm{~h}$ after ultrasound treatment. In sharp contrast, the same dose of free liposomes (from the same liposome batch) (Figure 5C) resulted in a clear liposome accumulation in all inflamed joints already $4 \mathrm{~h}$ after injection. The absolute radiance values of the displayed joints can be retrieved 
in Supplementary Figure S8. While the fluorescent signal, representative for liposome accumulation, further increased over the following $24 \mathrm{~h}$ (Figure 5D), the accumulation was also more pronounced for those joints that had a higher CIA score, similar to what has been observed by Gawne et al. [91]. This indicates that there was a clear relation between liposome accumulation and the level of inflammation.

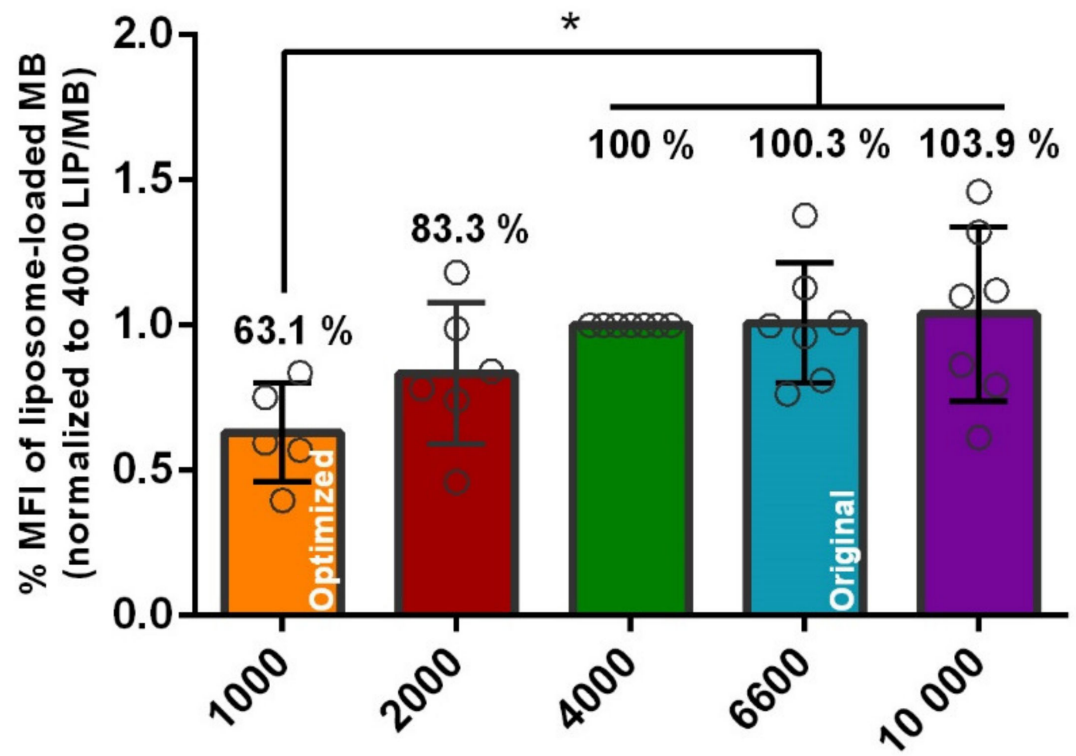

Ratio liposomes per MB

Figure 4. Optimization of liposome-loaded microbubbles to minimize the fraction of free liposomes. Flow cytometric analysis of the mean fluorescence intensity (MFI) of the different liposome-loaded microbubble formulations normalized to the MFI of the 4000 liposomes/MB formulation (green bar). Different numbers of liposomes were added to the biotinylated microbubbles and MFIs were compared via one-way ANOVA with Tukey's correction for multiple testing, at least $n=5$ replicates (dots represent individual data points) for each volume, ${ }^{*}$ represents $p<0.05$.

Interestingly, when liposomes were coupled to the microbubbles, they were cleared much faster from circulation. As quickly as $30 \mathrm{~min}$ after microbubble injection, liposome fluorescence was only detected in the liver (Figure 5A,B). Subsequent imaging at 4 and $24 \mathrm{~h}$ after microbubble injection showed a further decrease of the liver fluorescence, indicating liposomal degradation, which can be related to efficient uptake in the quickly degrading Kupffer cells [96-98]. This was also confirmed by ex vivo imaging (Figure 5E,F) as only a minor signal was detected in the spleen, but no fluorescence could be found in the inflamed joints. The liposomes from the free liposomes-injected mice (Figure 5C) showed a much longer circulation time (i.e., remaining fluorescence in the blue circle up to $4 \mathrm{~h}$ ) as well as a clear accumulation in the inflamed joints. Additionally, in this case, joint accumulation was confirmed by ex vivo fluorescence imaging (Figure 5F). We also measured fluorescence in the liver and spleen which corresponds to earlier biodistribution data of long-circulating PEGylated liposomes [91,92]. 

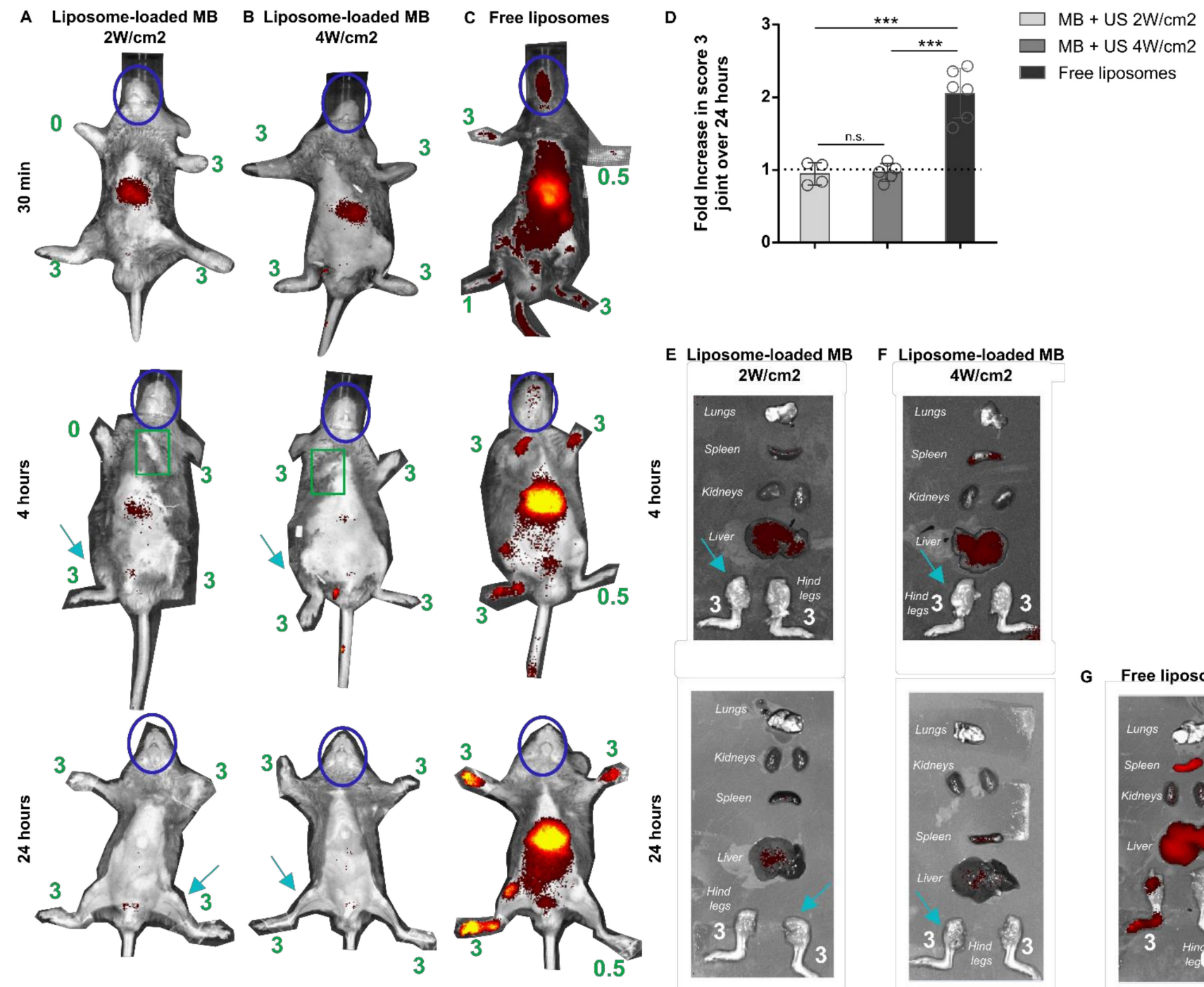

G Free liposomes
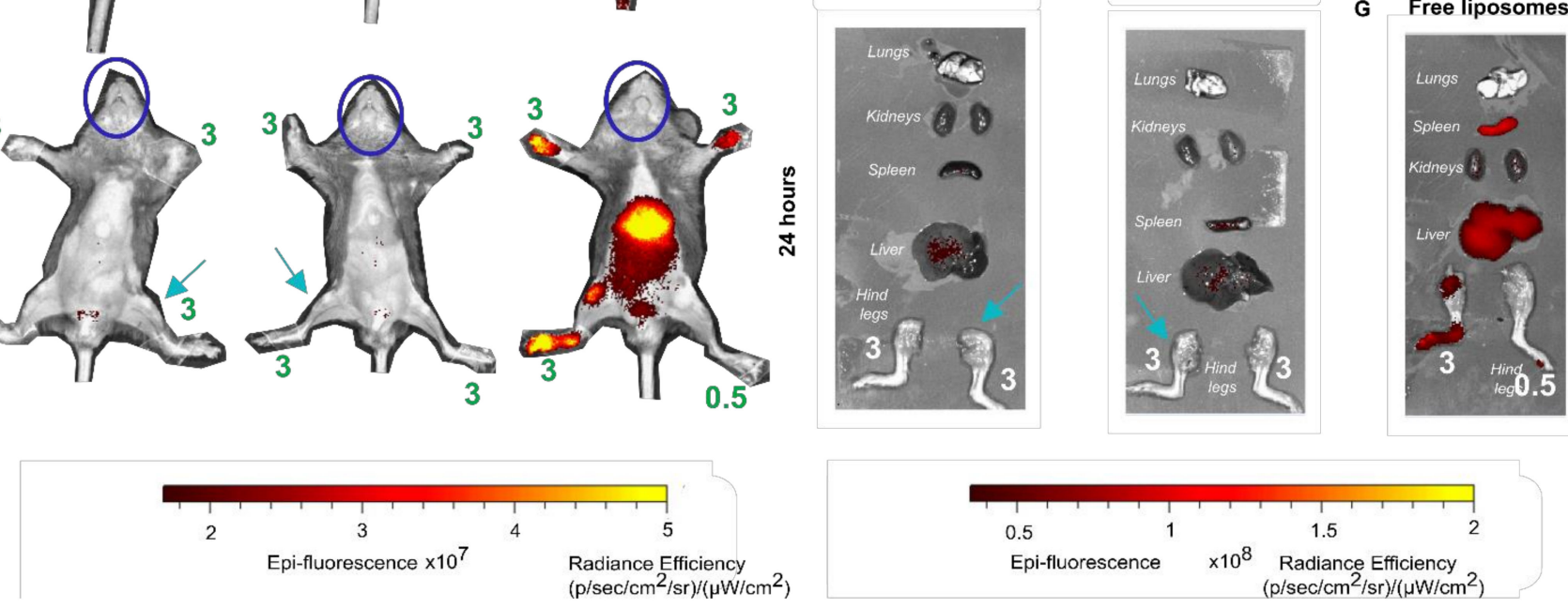

Figure 5. Representative whole body fluorescent images to illustrate the biodistribution of fluorescently labelled liposomes. Representative whole body $(\mathbf{A}-\mathbf{C})$ and ex vivo organ fluorescence images (E-G) of DiR liposomes after injection of liposome-loaded microbubbles $(\mathbf{A}, \mathbf{B}, \mathbf{E}, \mathbf{F})$ or the same dose of liposomes $(\mathbf{C}, \mathbf{G})$. One knee joint with a CIA score 3 of microbubble-injected mice were treated with therapeutic ultrasound of $1 \mathrm{MHz}$ with an acoustic pressure of $2 \mathrm{~W} / \mathrm{cm}^{2}(\mathbf{A}, \mathbf{E})$ or $4 \mathrm{~W} / \mathrm{cm}^{2}$ $(\mathbf{B}, \mathbf{F})$ and is indicated by a blue arrow. Whole body fluorescence images were taken at $30 \mathrm{~min}, 4$ and $24 \mathrm{~h}$ after liposome or microbubble injection. $n=2$ replicates for each ultrasound condition and $n=3$ for the liposome only condition. The CIA score of the front paws and ankles of the mice is displayed next to each limb. A green square is added as a visual aid to locate the front paw. The 'throat-neck' area was used to estimate the liposomes in circulation and is indicated by a blue circle. (D) Overview of fluorescence increase over $24 \mathrm{~h}$ after injection of the liposome-loaded microbubbles in CIA score 3 US-treated knees either exposed to a therapeutic ultrasound pulse of 2 or $4 \mathrm{~W} / \mathrm{cm}^{2}$ (each dot represents a treated knee), and score 3 joints (including knees, front paws, and ankles (each dot represents a score 3 joint)) in mice that were injected the exact same amount of free liposomes. Different treatment groups were compared via one-way ANOVA, with Tukey's correction for multiple testing, asterisks: ${ }^{* * *}$ respectively represent $p<0.001$. 


\section{Discussion}

In human patients, CEUS is clinically well-established for microvascular imaging [22,42] and potentially useful to monitor the progress of RA in the joint synovium $[99,100]$. While liposomes, loaded with small molecular, anti-inflammatory drugs (i.e., NSAIDs, corticosteroids, or methotrexate) have already shown therapeutic success in RA by selectively accumulating in the inflamed synovium [1,101-103], in the current study we investigated whether liposome-loaded microbubbles can be used to further stimulate the selective delivery of liposomes to the inflamed joints under therapeutic ultrasound guidance. We made use of the collagen-induced arthritis (CIA) mouse model [78] as this model closely resembles human RA pathogenesis. First, the diagnostic potential of CEUS was evaluated in CIA mice. Although ultrasound imaging of the joint synovium is more complex due to the presence of surrounding articulate bones (i.e., femur and tibia in the knee joint) (Figure 2B), the synovial cavity and synovial microbubble influx could be clearly visualized (Figure 2D). However, we could not detect any differences in the maximal contrast enhancement and time to peak of the contrast-enhanced ultrasound signal between healthy and inflamed synovia, which differs from results obtained in humans [12,71-73]. A possible explanation for this discrepancy may lie in the difference in microvasculature size between humans and mice. Whereas the microvasculature in human knee joints $(\mathrm{d}=11 \mu \mathrm{m})$ [104] is known to be large enough to permit CEUS imaging with micron-sized microbubbles $[12,71,73]$, Raatz et al. determined that the murine neo-vasculature in CIA knee synovia is about 2-times smaller $(\mathrm{d}=5.8 \mu \mathrm{m})$, which may already hamper efficient microbubble perfusion [81]. In addition, Raatz et al. found that the functionality of the synovial vasculature is significantly decreased [81,105,106]. Similarly, Dewitte et al. have shown that lymphatic drainage of microbubbles after subcutaneous injection was seriously hampered in mice while this was not the case for larger research animals like dogs [74].

Despite this discrepancy, the clear influx of microbubbles in the joint synovium allowed us to further explore the therapeutic value of liposome-loaded microbubbles. Initial wholebody fluorescence imaging experiments illustrated that the large fraction of free liposomes, that were co-injected with the liposome-loaded microbubbles, passively accumulated in inflamed joints. A subsequent experiment, performed using either an optimized microbubble formulation (minimizing the free liposome fraction) or the equivalent dose of free liposomes, demonstrated that free liposomes clearly outperformed the liposome-loaded microbubble formulations; only in mice that received free liposomes, (high) fluorescence in the inflamed joints was measured. In addition, liposomes that were coupled to the microbubbles were cleared much faster from circulation and were only shortly detected in the liver. This clearly confirmed that the liposome accumulation in the inflamed joints observed using the original formulation was caused by the residual free liposome fraction that was co-injected with the microbubbles in the original liposome-loaded microbubble formulation.

An important explanation for our results could also relate to the exact ultrasound dose that reaches the synovial vasculature. The acoustic mismatch between the articulate bones and surrounding soft tissue might hamper well-controlled ultrasound delivery and limit microbubble cavitation activity [16]. Although bony structures are generally considered reflectors, this is very likely not the case for the thin murine fibula and tibia. As the latter have a thickness on the order of the millimetre and are thus comparable to the $1.5 \mathrm{~mm}$ wavelength of the $1 \mathrm{MHz}$ therapeutic ultrasound pulse, the anatomic structure in the murine model is expected to scatter rather than reflect ultrasound [99], which is a fundamentally different interaction. Secondly, the overall geometry of the setup in combination with the tiny mouse knee further complicates the evaluation of the delivered ultrasound dose. The transducer is partly in contact with air, which changes its response, and the tin mouse leg is backed by a hard structure, likely to reflect ultrasound and generate uncontrolled standing waves. Knowing the pressure in situ is indispensable to evaluate the exact ultrasound dose delivered and estimate the effect on microbubble cavitation. In this study, however, and similarly to the majority of preclinical studies with therapeutic ultrasound and microbubbles [64], we currently lack knowledge about the ultrasound 
regimen and associated microbubble behaviour in situ. For microbubble-mediated drug delivery in general, it will therefore be essential to better monitor the exact microbubble response during ultrasound exposure in vivo to allow improved therapeutic ultrasound, however, no such techniques are available on the market today [64].

Our CEUS experiments indicated that we were able to measure contrast signal from the synovium, which suggests that the diagnostic ultrasound beam with a frequency of 13-24 MHz was able to reach the synovium but cannot be directly correlated to the effect of a $1 \mathrm{MHz}$ therapeutic ultrasound beam for the aforementioned reasons. In addition, others have successfully delivered nanotherapeutics in the synovium of rodents with similar ultrasound settings. Zhu et al. observed enhanced therapeutic effects of dexamethasone when combined with intravenously injected ultrasound-responsive nanodroplets to therapeutic ultrasound $\left(1 \mathrm{MHz}, 3 \mathrm{~W} / \mathrm{cm}^{2}\right)$ in the ankle joints of rats [107]. Although they did not elaborate on the exact positioning of the ultrasound transducer and neither showed CEUS data, this illustrates that therapeutic ultrasound can reach the ankle synovium of rats. A major difference with our study is that the authors made use of rats and ultrasound responsive nanodroplets. The latter are considered as alternatives for microbubbles as they consist of a superheated liquid core that can turn into a gaseous microbubble upon ultrasound exposure $[60,64,108]$. The main advantage is that they have a much smaller size $(130-320 \mathrm{~nm})$ than micron-sized microbubbles and are therefore expected to more easily pass through rodent neovasculature.

Other groups have investigated ultrasound-triggered drug delivery after direct intraarticular injections of microbubbles in rabbit joints [109] and mice joints [85]. They showed a clearly enhanced gene expression after ultrasound treatment although it is important to mention that intra-articular injections might result in much higher, local microbubble concentration compared to intravenous injections. Moreover, the major difference between these reports and the present study is that, in these other studies, microbubbles were co-injected together with the nanomedicines, while we loaded them on microbubbles.

Our results illustrate that by loading liposomes onto the microbubble-shell, a much quicker hepatic elimination of the liposomes occurs compared to the free circulating analogs (Figure 5). The ex vivo images (Figure 5D-F) showed that the majority of all liposome fluorescence in microbubble-injected mice was found in the liver and, to a minor extent, in the spleen. Ferrara et al. described that the main reasons for microbubble clearance are the dissolution of the microbubble, uptake by highly phagocytic cells types [110], and filtering of the microbubbles by lungs and spleen; our results demonstrate that the liver, and to a minor extent the spleen, serve as the major elimination routes for microbubbles as we were unable to detect any fluorescence in the lungs. This corroborates similar observations by Sirsi et al. who showed that microbubble filtration in the lungs was negligible in vivo [111]. The signal derived from the liver and spleen is very likely due to the uptake of the microbubbles in phagocytic macrophages [111], better known as Kupffer cells in the liver and red pulp macrophages in the spleen, as shown before by many other groups [112-116]. It is known that the passage of the larger microbubbles is impeded through endothelial liver fenestrae in mice $(d=140-150 \mathrm{~nm})$ and human liver $(\mathrm{d}=150-175 \mathrm{~nm})[98,115,117,118]$, but instead stimulates their engulfment by highly phagocytic Kupffer cells that are present throughout the liver [115]. The uptake in these highly metabolic Kupffer cells can also explain the fast disappearance of fluorescent signal in the liver, as lipid structures are known to be degraded in Kupffer cells with a half-life of about $2-3 \mathrm{~h}$ similar to the kinetics we observed (Figure 5) [96]. Kupffer cells play an important function in host defense as they remove apoptotic cells and micron-sized compounds from the circulation [115,119]. Apart from the microbubble size, the microbubble shell composition and surface properties are known to influence microbubble opsonization and therefore also govern their recognition and uptake by Kupffer cells $[22,114,120,121]$. Yanagisawa et al. compared the uptake of five different microbubble formulations by Kupffer cells and concluded that especially Sonazoid ${ }^{\mathrm{TM}}$ and Optison ${ }^{\mathrm{TM}}$ microbubbles are quickly removed from circulation by Kupffer cells [114]. The former are composed of phosphatidylserine [114,115], which also marks 
apoptotic cells and as such increases the recognition by activated macrophages such as Kupffer cells [122,123]. A way to overcome the fast opsonization of microbubbles in the blood is by implementing a PEG-shell, a hydrophilic shielding molecule that drastically reduces the binding of opsonines [22,112,114,124-126]. For this reason, we used PEGylated microbubbles that were coupled to PEGylated liposomes [89,127]. Nevertheless, although, PEGylation is known to retard the opsonization process, the bigger size of the microbubbles will probably stimulate their uptake by highly phagocytic cells [113,128]. Inevitably, microbubble-loaded liposomes are prone to a fast clearance by Kupffer cells in the liver as has been frequently reported before for several types of microbubbles [112-115,120]. Usage of the previously discussed smaller ultrasound-responsive nanodroplets that can be similarly loaded with liposomes as described by Honari et al. [129], will likely enhance both the neovascular penetration and sustain longer circulation times [130,131] as they are less quickly captured in the liver. In this way, they might tackle some of the limits observed using microbubbles in murine arthritis. However, it is important to note that regardless, the difference in ultrasound interface between murine and human joint structure remains unchanged. As nanodroplets require higher ultrasound energies to enable their transition into contrast-enhancing microbubbles [31,64], it remains to be studied whether this is feasible in murine joints.

The slower fluorescence decay in the liver observed for PEGylated liposomes over time (Figure 5E) is related to their smaller size and hence longer circulation time as this allows (i) a more sustained accumulation in Kupffer cells over time [97,112] and (ii) passage through the hepatic sinusoid fenestrae enabling access to other more slowly degrading hepatic cell subsets such as hepatocytes $[97,98,112]$.

Other groups have clearly shown improved therapeutic outcomes with nanoparticleloaded microbubbles in tumor models, where one may expect a more pronounced microbubble influx. This influx is a prerequisite to achieve sufficient drug concentrations at the target site in case of drug-loaded microbubbles [64,65,68,132]. A major difference with therapeutic studies that make use of co-delivery of microbubbles and small molecular weight drugs is that sonoporation effects can persist for hours [64,133-135], and thus provide a much longer timeframe for the co-delivered drugs to extravasate as the drug circulation time is not limited to the circulation time of (undestroyed) microbubbles [64]. Our study also illustrates that it is important to optimize nanoparticle-loaded microbubble formulations in such a way that the free nanoparticle fraction is minimized. Only with these optimized formulations the exact fraction of nanoparticles that become directly deposited in the ultrasound-treated region can be estimated. It is generally accepted that the EPR effect also plays a major role in nanoparticle accumulation in murine tumors and as most therapeutic studies evaluate therapeutic effects over a much longer timeframe than the circulation time of the bubbles, future studies have to clarify to which extent ultrasound treatment can further stimulate extravasation of long-circulating nanoparticles [52,68,132,136-139].

\section{Materials and Methods}

\subsection{Liposomes}

The liposomes were obtained via the lipid film hydration technique as reported by Avnir et al. [140,141] The liposomes consisted of DSPC (1,2-distearoyl-sn-glycero-3phosphocholine) (Corden Pharma, Liestal, Switzerland), Cholesterol (Avanti Polar Lipids, Alabaster, AL, USA) and DSPE-PEG 2000 (1,2-distearoyl-sn-glycero-3-phosphoethanol-amine$\mathrm{N}$-(biotinyl(polyethyleneglycol)-2000) (Avanti Polar Lipids, Alabaster, AL, USA) in 45:40:15 molar ratio (MR) ratio. The lipid films were rehydrated in HEPES buffer (20 mM, pH 7.4) leading to a final lipid concentration of $20 \mathrm{mg} / \mathrm{mL}$. The liposomes were downsized with a tip sonicator (Branson Digital Sonifier 450, Marshall Scientific, Hampton, NH, USA). The liposomes were further concentrated using a centrifugation step at $35,000 \times g$ for $1 \mathrm{~h}$ at $25{ }^{\circ} \mathrm{C}$ (L8-70M ultracentrifuge equipped with SW55Ti Rotor, Beckman Coulter Life Sciences, Indianapolis, IN, USA), the pellet is resuspended afterwards in a smaller volume to obtain $100 \mathrm{mg} / \mathrm{mL}$ liposomes. The final concentration of liposomes obtained averaged 
$1 \times 10^{14}$ liposomes $/ \mathrm{mL}$ and was measured using nanoparticle tracking analysis (NTA) with the Nanosight ${ }^{\circledR}$ (Malvern Instruments Ltd., Worcestershire, UK) in scatter mode.

The shelf-life was further monitored while stored at $4{ }^{\circ} \mathrm{C}$ to estimate the shelf-life stability. The liposomes had a size of $180 \mathrm{~nm}$ and remained stable at $4{ }^{\circ} \mathrm{C}$ for at least one month.

For fluorescently labelled liposomes, lipid fluorescent dye DiR/DiD (Molecular Probes ${ }^{\mathrm{TM}}$, Thermo Fisher Scientific, Waltham, WA, USA) was dissolved in chloroform and added in respectively 1.2 molar ratio of the total lipid amount to the lipid mixtures (as described above) before lipid film hydration. Inserting a lipophilic dye like DiD or DiR did not influence the size or surface charge of the liposomes.

\subsection{Size and Zeta-Potential and Concentration of the Liposomes}

The size and zeta-potential of the liposomes and LNPs dispersed in HEPES buffer (20 mM, pH 7.4) were characterized via Dynamic Light Scattering using a Malvern Zetasizer Nano-ZS (Malvern Instruments Ltd., Worcestershire, UK).

\subsection{Microbubbles}

Microbubbles are prepared in a 85:15 molar ratio of respectively DPPC (1,2-dipalmitoylsn-glycero-3-phosphocholine) (Avanti Polar Lipids, Alabaster, AL, USA) and DSPE-PEG $3400^{-}$ biotin (1,2-distearoyl-sn-glycero-3-phosphoethanol-amine-N-(biotinyl(polyethyleneglycol)3400)) (Laysan Bio Inc, Arab, AL, USA). The preparation of the microbubbles was done via lipid hydration as earlier reported by our group $[67,70,74,142,143]$. To summarize, appropriate amounts of lipids-dissolved in chloroform-were transferred to a round bottom flask and the obtained mixture was evaporated in a rotavapor at $65^{\circ} \mathrm{C}$. The lipid film was hydrated using a preheated mixture of HEPES buffer $(20 \mathrm{mM}, \mathrm{pH}$ 7.4), propylene glycol, and glycerol (in a resp. 7:2:1 ratio) resulting in a solution with a lipid concentration of $0.75 \mathrm{mg} / \mathrm{mL}$. Aliquots of the mixture were transferred to chromatography vials and the headspace was filled with $\mathrm{C}_{4} \mathrm{~F}_{10}$ gas (F2 chemicals, Preston, UK). To activate the microbubbles, vials were shaken for $15 \mathrm{~s}$ with a Capmix ${ }^{\mathrm{TM}}$ device (3M-ESPE, Diegem, Belgium). Subsequently, three washing steps were performed to remove free lipids and the excess of avidin before liposomes are coupled. After activation, the microbubbles were washed by centrifugation using HEPES buffer. After the first washing step, avidin (100 mg/mL, IBA GmbH, Göttingen, Germany) was added in excess and left to incubate for $5 \mathrm{~min}$ to couple to the biotin groups. Subsequently, 2 centrifugation washing steps were performed (750 g for 5 min at room temperature) with HEPES buffer to remove the unbound avidin after which the avidinylated microbubbles were resuspended in the required volume of dextrose $5 \%$. The final concentration of microbubbles obtained averaged $1.1 \times 10^{9}$ microbubbles $/ \mathrm{mL}$ and size distribution was determined by Coulter Counter (Multisizer 4, Beckman Coulter Life Sciences, Villepinte, France). Liposomes were added to the final avidinylated microbubble suspension and left to incubate for $5 \mathrm{~min}$ after which liposome-loaded microbubbles were intravenously injected without removal of any free liposomes in the sample.

\subsection{Stability of Microbubble Loading}

The stability of the liposome loading of the microbubbles was also evaluated via flow cytometry (Cytoflex, Beckman Coulter Life Sciences, Villepinte, France). After 5 min of liposome incubation with avidinylated microbubbles, $100 \mu \mathrm{L}$ of the suspension was diluted in $1 \mathrm{~mL}$ HEPES buffer or filtered fetal bovine serum (FBS) (South American Origin, Biowest) to detect possible liposome release in serum environment. The difference in microbubble loading between HEPES and serum was determined via flow cytometry.

\subsection{Optimization of Microbubble Loading}

Within this work, two different liposome-loaded microbubble formulations were used referred to as the 'original' formulation and the 'optimized' formulation. The 'orig- 
inal' formulation consists of $33 \mu \mathrm{L}$ liposomes added to $500 \mu \mathrm{L}$ microbubble suspension or a liposome/MB ratio of 6600. In this formulation, a significant amount of free liposome was found. The 'optimized' formulation consisted of $5 \mu \mathrm{L}$ liposomes that were added to $500 \mu \mathrm{L}$ microbubbles or a liposomes/MB ratio of 1000 . For the liposome optimization assay in general, different volumes of the same DiD-labelled liposome sample; i.e., 5, 10, 20, 33, and $50 \mu \mathrm{L}\left(10^{14}\right.$ liposomes $\left./ \mathrm{mL}\right)$ were added to $500 \mu \mathrm{L}$ of microbubbles $\left(1.1 \times 10^{9}\right.$ microbubbles $\left./ \mathrm{mL}\right)$ and incubated for $5 \mathrm{~min}$. This respectively equalled a liposome/MB ratio of 1000, 2000,4000, 6600, and 10,000. Subsequently, $100 \mu \mathrm{L}$ of the liposome-microbubble suspension was transferred to $1 \mathrm{~mL}$ of HEPES buffer and immediately measured using flow cytometry (Cytoflex, Beckman Coulter) and subsequently analyzed using FlowJo ${ }^{\circledR}$ software (BD company, Erembodegem, Belgium).

\subsection{Confocal Microscopy}

The liposome-loaded microbubbles were also visualized via confocal imaging (C1-si confocal microscope, Nikon, Amsterdam, The Netherlands) after coupling to the fluorescently labeled liposomes. A drop of the liposome-microbubble solution was put onto a glass slide with a cover slip whereafter the liposome distribution on the microbubble shell was explored with a $60 \times$ oil immersion objective (Plan Apo Nikon, Amsterdam, The Netherlands), using $637 \mathrm{~nm}$ later to excite the DiD dye in the liposomal bilayer.

\subsection{Laboratory Animals (Mice)}

Male DBA/1 and C57BL/6 mice were purchased from Janvier (Le Genest Saint Isle, France). The C57BL/6 mice were solely used to validate the positioning of the mice. All animals were housed in a specific-pathogen-free (SPF) facility following institutional guidelines. All animal experiments were conducted according to the regulations of the Belgian law and approved by the local Ethical Committee on Animal Experiments (Ghent University, ECD 18/16). Mice were kept in controlled conditions (12 h/12 h light/dark cycle, temperature $21-24{ }^{\circ} \mathrm{C}$, relative humidity $40-70 \%$ ) and had access to food and water ad libitum.

\subsection{Collagen-Induced Arthritis Model}

The collagen-induced arthritis (CIA) model was induced in male DBA/1 and C57BL/6 mice via intradermal injection at the base of the tail consisting of $200 \mu \mathrm{g}$ of chicken type II collagen (CII) (Morwell Diagnostics GmbH, Zurich, Switzerland) dissolved in $0.1 \mathrm{M}$ acetic acid, emulsified in Incomplete Freund's Adjuvant with respectively $150 \mu \mathrm{g}(\mathrm{DBA} / 1)$ and $200 \mu \mathrm{g}$ (C57BL/6) mycobacterium Tuberculosis H37RA (Difco, Lawrence, KS, USA). After 21 days, a booster intradermal injection was given consisting of $200 \mu \mathrm{g}$ CII in Incomplete Freund's Adjuvant (DBA/1) or $200 \mu \mathrm{g}$ CII emulsified in incomplete Freund's Adjuvant with $250 \mu \mathrm{g}$ mycobacterium Tuberculosis H37RA (C57BL/6). From day 21, the mice were monitored three times a week for clinical symptoms of collagen-induced arthritis. The severity of the inflammation was scored visually, based on erythema and swelling and graded; $0=$ normal; $0.5=$ erythema and edema in only one digit; $1=$ erythema and mild edema of the footpad, or ankle or two to five digits; 2 = erythema and moderate edema of two joints (footpad, ankle, two to five digits); 3 = erythema and severe edema of the entire paw; 4 = reduced swelling and deformation leading to incapacitated limb. A CIA score of 3 present in at least one knee joint was required for the experiments. The monitoring was done until the mice were sacrificed (maximally up to 42 days post-immunization).

\subsection{CEUS Imaging of Joints}

To validate the positioning of the mice for ultrasound treatment, control C57BL/ 6 mice were used. For contrast-enhanced ultrasound imaging of joints, unloaded microbubbles were injected in healthy DBA/1 mice and the influx of the microbubbles in the joints was monitored. The mice were anesthetized using 3.5\% isoflurane (Isoflo ${ }^{\circledR}$, AST Farma, Oudewater, The Netherlands) gas in oxygen. Once anesthetized, the knees were depilated 
with Veet ${ }^{\circledR}$ to remove the excess of fur in order to avoid air bubbles during ultrasound imaging. A catheter (polyethylene tubing, Intramedic PE10, BD company, Erembodegem, Belgium) filled with a sterile $0.9 \% \mathrm{NaCl}$ solution was placed in the lateral tail vein and fixed with tissue glue (Vetbond ${ }^{\circledR}, 3 \mathrm{M}$-ESPE, Diegem, Belgium) to enable further manipulations. Subsequently, the mouse was placed supine while tilting the knee joint at a 90-degree angle. The knee was fixed with tape to ensure stability during the ultrasound visualisation. Ultrasound gel was applied on top of the fixed knee. For contrast ultrasound, the VEVO 2100 device coupled with the MS-250 transducer (VisualSonics, Amsterdam, The Netherlands) was placed perpendicular onto the knee, aligned with the femur. Once the synovial region (Figure 3A) was correctly visualized, an injection of $50 \mu \mathrm{L}$ uncoupled microbubble solution $\left(1.1 \times 10^{9}\right.$ microbubbles $\left./ \mathrm{mL}\right)$, suspended in an isotonic dextrose $5 \%$ solution, was performed and the contrast-enhancement was recorded. This was done both in healthy and CIA-induced DBA/1 mice.

\subsection{Therapeutic Ultrasound Treatment of Mice}

Mice were treated similarly as explained before (anesthetized, Veet ${ }^{\circledR}$, catheter, positioning, and microbubble injection). The microbubbles were loaded with fluorescently labelled (DiR) liposomes; the original formulation contained $33 \mu \mathrm{L}$ liposomes $(100 \mathrm{mg} / \mathrm{mL}$ lipids) per $500 \mu \mathrm{L}$ microbubbles; the optimized formulation contained $5 \mu \mathrm{L}$ liposomes $(100 \mathrm{mg} / \mathrm{mL}$ lipids) per $500 \mu \mathrm{L}$ microbubbles. Liposomes were added to the final avidinylated microbubble suspension and left to incubate for $5 \mathrm{~min}$, after which $200 \mu \mathrm{L}$ was intravenously injected. The 'liposome-only' control contains $5 \mu \mathrm{L}$ liposomes $/ 500 \mu \mathrm{L}$ isotonic $5 \%$ dextrose solution, whereafter $200 \mu \mathrm{L}$ was intravenously injected. After microbubble injection, ultrasound exposure of the knee joint was established using a Sonitron device (Sonitron 2000; Rich-Mar, Inola, OK, USA) using the following parameters: pressure of $2 \mathrm{~W} / \mathrm{cm}^{2}$ or $4 \mathrm{~W} / \mathrm{cm}^{2}, 30 \mathrm{~s}$ exposure time, $20 \%$ duty cycle and 2000 cycles per pulse. Ultrasound treatment was started $10 \mathrm{~s}$ after intravenous injection of liposome-loaded microbubbles as this time point corresponded with the onset of the microbubble influx into the synovium, as determined before in the CEUS experiment (Figure 2D). Only the knee with a CIA score of 3 was exposed to therapeutic ultrasound, whereas all score 3 joints of the non-treated mice (including knees, front paws, and ankles) served as a reference. In the treated mice, a check-up by contrast ultrasound (VEVO 2100 — as described earlier) was done to ensure that all microbubbles have been destructed.

\subsection{In Vivo Biodistribution}

The biodistribution of intravenously injected DiR liposomes was monitored over time via an IVIS lumina II (PerkinElmer, Waltham, MA, USA) in the far-red region at $745 \mathrm{~nm}$. In order to properly image the presence of the liposomes in the major organs, the body and limbs of the mice were depilated to maximize the fluorescence to be picked up by the IVIS device. Fluorescence images were acquired (acquisition time: $1 \mathrm{~s}$ ) following excitation at $745 \mathrm{~nm}$ using an ICG emission filter. To determine the blood circulation time of the liposomes, the fluorescence from liposomes in the fur-less 'throat-neck' area was measured, allowing estimation of the residual fluorescence from the blood circulation. Quantification of the fluorescence images was done using the Living Image software (PerkinElmer, Waltham, MA, USA).

\subsection{Statistical Analysis}

The applicable statistical test is mentioned underneath each graph. Statistical analysis is performed using SPSS (IBM SPSS Statistics for Windows, version 28 (IBM Corp., Armonk, NY, USA) and GraphPad Prism 6 (GraphPad software, San Diego, CA, USA). Significance levels are indicated with asterisks: ${ }^{*}, * *$ and ${ }^{* * *}$ respectively represent $p<0.05 ; p<0.01$ and $p<0.001$. 


\section{Conclusions}

We observed that murine arthritis models are not well-suited to evaluate the theranostic potential of liposome-loaded microbubbles for RA purposes. Despite the clinical use of (CE)US for the detection of neo-angiogenesis in humans, the evaluation in mice was hampered by both physiological and technological concerns. Whereas the technological concerns are likely to be overcome in the future, the physiological issues, which include severely restricted microbubble passage in murine synovial vasculature and the size of the murine joints, will not. As the size of the murine joints hinders both, control over the exact ultrasound conditions in situ, and the translation of the observations to a clinical setting, larger preclinical animals will be crucial to accurately evaluate the true potential of liposome-loaded microbubbles for RA therapy.

Supplementary Materials: The following supporting information can be downloaded at: https: / / www.mdpi.com/article/10.3390/scipharm90010017/s1, Figure S1: Physicochemical characterization of liposomes, Figure S2: Liposome coupling to microbubbles-flow cytometry gating strategy, Figure S3: Liposome-loading of microbubbles, Figure S4: Visual CIA scoring, Figure S5: VEVO Liposome influx, Figure S6: Liposome accumulation-absolute radiance values of original formulation, Figure S7: Liposome-loaded microbubbles—optimization study, Figure S8: Liposome accumulationabsolute radiance values of optimized formulation.

Author Contributions: Conceptualization, I.L, P.J., D.E. and S.C.D.S.; methodology, J.D., I.L., S.R., H.D. and G.L.; software, C.V. and B.D.; formal analysis, J.D.; investigation, J.D., S.R., H.D., T.D. and J.C.; resources, S.C.D.S. and D.E.; writing—original draft preparation, J.D. and I.L.; writing-review and editing, S.R., H.D., S.C.D.S., G.L., M.V., P.J., D.E., B.D. and C.V.; visualization, J.D. and I.L.; supervision, I.L., D.E., P.J., G.L., M.V. and S.C.D.S.; project administration, J.D.; funding acquisition, I.L. and S.C.D.S. All authors have read and agreed to the published version of the manuscript.

Funding: This research was funded by Ghent University: BOF17/DOC/305 and European Union: Horizon 810685.

Institutional Review Board Statement: The animal study protocol was approved by the Ethics Committee on Animal Experiments of Ghent University, ECD number 18/16 on 9 April 2018.

Informed Consent Statement: Not applicable.

Data Availability Statement: Not applicable.

Acknowledgments: The authors would like to thank Toon Brans for his help with the confocal microscopy. Furthermore, we would like to thank Karlijn Debusschere for her help with the CEUS experiments. Joke Deprez and Silke Roovers are doctoral fellows funded by the Special Research Fund (BOF) from Ghent University, Flanders, Belgium. The support is gratefully acknowledged. The authors would equally like to acknowledge funding from the European Union's Horizon 2020 research and innovation program under grant agreement No 810685 (DelNam project). Biorender was used for designing the graphical abstract.

Conflicts of Interest: The Authors declares that there is no conflict of interest.

\section{References}

1. Scott, D.L.; Wolfe, F.; Huizinga, T.W.J. Rheumatoid arthritis. Lancet 2010, 376, 1094-1108. [CrossRef]

2. Firestein, G.; Mcinnes, I.B.; Jolla, L. Immunopathogenesis of rheumatoid arthritis. Immunity 2018, 46, 183-196. [CrossRef] [PubMed]

3. Yang, M.; Feng, X.; Ding, J.; Chang, F.; Chen, X. Nanotherapeutics relieve rheumatoid arthritis. J. Control. Release 2017, 252, 108-124. [CrossRef] [PubMed]

4. McInnes, I.B.; Schett, G. Pathogenetic insights from the treatment of rheumatoid arthritis. Lancet 2017, 389, 2328-2337. [CrossRef]

5. Morshed, A.; Abbas, A.B.; Hu, J.; Xu, H. Shedding New Light on The Role of $\alpha v \beta 3$ and $\alpha 5 \beta 1$ Integrins in Rheumatoid Arthritis. Molecules 2019, 24, 1537. [CrossRef]

6. Elshabrawy, H.A.; Chen, Z.; Volin, M.V.; Ravella, S. The pathogenic role of angiogenesis in rheumatoid arthritis. Angiogenesis 2015, 18, 433-448. [CrossRef]

7. Backhaus, M.; Burmester, G.R.; Gerber, T.; Grassi, W.; Machold, K.P.; Swen, W.A.; Wakefield, R.J.; Manger, B. Guidelines for musculoskeletal ultrasound in rheumatology. Ann. Rheum. Dis. 2001, 60, 641-649. [CrossRef] 
8. Wu, H.; Wu, H.; He, Y.; Gan, Z.; Zhou, M.; Liu, S.; Liu, H. Synovitis in mice with inflammatory arthritis monitored with quantitative analysis of dynamic contrast-enhanced NIR fluorescence imaging using iRGD-targeted liposomes as fluorescence probes. Int. J. Nanomed. 2018, 13, 1841-1850. [CrossRef]

9. Abma, E.; Stock, E.; de Spiegelaere, W.; van Brantegem, L.; Vanderperren, K.; Ni, Y.; Vynck, M.; Daminet, S.; de Clercq, K.; de Rooster, H. Power Doppler ultrasound and contrast-enhanced ultrasound demonstrate non-invasive tumour vascular response to anti-vascular therapy in canine cancer patients. Sci. Rep. 2019, 9, 9262. [CrossRef]

10. Kaeley, G.S.; Bakewell, C.; Deodhar, A. The importance of ultrasound in identifying and differentiating patients with early inflammatory arthritis: A narrative review. Arthritis Res. Ther. 2020, 22, 1. [CrossRef]

11. Dougados, M.; Devauchelle-Pensec, V.; Ferlet, J.; Agostino, M.D.; Backhaus, M.; Bentin, J.; Chalès, G.; Chary-valckenaere, I.; Conaghan, P.; Wakefi, R.J.; et al. The ability of synovitis to predict structural damage in rheumatoid arthritis: A comparative study between clinical examination and ultrasound. Ann. Rheum. Dis. 2013, 72, 665-671. [CrossRef] [PubMed]

12. Stramare, R.; Raffeiner, B.; Ciprian, L.; Scagliori, E.; Coran, A.; Perissinotto, E.; Fiocco, U.; Beltrame, V.; Rubaltelli, L. Evaluation of finger joint synovial vascularity in patients with rheumatoid arthritis using contrast-enhanced ultrasound with water immersion and a stabilized probe. J. Clin. Ultrasound 2012, 40, 147-154. [CrossRef] [PubMed]

13. Terslev, L.; D’Agostino, M.A.; Brossard, M.; Aegerter, P.; Balint, P.; Backhaus, M.; Bruyn, G.A.; Chary-Valckenare, I.; Filippucci, E.; Freeston, J.; et al. Which Knee and Probe Position Determines the Final Diagnosis of Knee Inflammation by Ultrasound ? Results from a European Multicenter Study, Ultraschall Der Medizin. Eur. J. Ultrasound 2012, 33, 173-178. [CrossRef]

14. Torp-Pedersen, S.; Christensen, R.; Szkudlarek, M.; Ellegaard, K.; Agostino, M.A.D.; Iagnocco, A.; Naredo, E.; Balint, P.; Wakefield R.J.; Torp-pedersen, A.; et al. Power and Color Doppler Ultrasound Settings for Inflammatory Flow Impact on Scoring of Disease Activity in Patients with Rheumatoid Arthritis. Arthritis Rheumatol. 2015, 67, 386-395. [CrossRef]

15. Clavel, G.; Renault, G.; Boissier, M.; Fradelizi, D.; Bessis, N. Ultrasound and Doppler micro-imaging in a model of rheumatoid arthritis in mice. Ann. Rheum. Dis. 2008, 67, 1765-1772. [CrossRef] [PubMed]

16. Chang, K.-V.; Lew, H.L.; Wang, T.-G.; Chen, W.-S. Use of Contrast-Enhanced Ultrasonography in Musculoskeletal Medicine. Am. J. Phys. Med. Rehabil. 2012, 91, 449-457. [CrossRef]

17. Cai, X.H.; Yang, S.P.; Shen, H.L.; Lin, L.Q.; Zhong, R.; Wu, R.M.; Lv, G.R. Application of contrast-enhanced ultrasonography and ultrasonography scores in rheumatoid arthritis. Int. J. Clin. Exp. Med. 2015, 8, 20056-20064.

18. Meyerowitz, C.B.; Fleischer, A.C.; Pickens, D.R.; Thurman, G.B.; Borowsky, A.D.; Thirsk, G.; Hellerqvist, C.G. Quantification of tumor vascularity and flow with amplitude color Doppler sonography in an experimental model: Preliminary results. $J$. Ultrasound Med. 1996, 15, 827-833. [CrossRef]

19. Xu, H.; Bouta, E.M.; Wood, R.W.; Schwarz, E.M.; Wang, Y.; Xing, L. Utilization of longitudinal ultrasound to quantify joint soft-tissue changes in a mouse model of posttraumatic osteoarthritis. Bone Res. 2017, 5, 17012. [CrossRef]

20. Stride, E. Physical principles of microbubbles for ultrasound imaging and therapy. Front. Neurol. Neurosci. 2015, 36, 11-22. [CrossRef]

21. Izadifar, Z.; Babyn, P.; Chapman, D. Ultrasound Cavitation/Microbubble Detection and Medical Applications. J. Med. Biol. Eng. 2019, 39, 259-276. [CrossRef]

22. Paefgen, V.; Doleschel, D.; Kiessling, F. Evolution of contrast agents for ultrasound imaging and ultrasound-mediated drug delivery. Front. Pharmacol. 2015, 6, 197. [CrossRef] [PubMed]

23. Thomas, A.N.; Stride, E. An Indispensable tool for ultrasound based diagnostics and therapies-Microbubbles. J. Nuffield Dep. Surg. Sci. 2020, 1, 3. [CrossRef]

24. Al-Jawadi, S.; Thakur, S.S. Ultrasound-responsive lipid microbubbles for drug delivery: A review of preparation techniques to optimise formulation size, stability and drug loading. Int. J. Pharm. 2020, 585, 119559. [CrossRef]

25. Martin, K.H.; Dayton, P.A. Current status and prospects for microbubbles in ultrasound theranostics. Wiley Interdiscip. Rev. Nanomed. Nanobiotechnol. 2013, 5, 329-345. [CrossRef]

26. Qin, S.; Caskey, C.F.; Ferrara, K.W. Ultrasound contrast microbubbles in imaging and therapy: Physical principles and engineering. Phys. Med. Biol. 2009, 54, 27-57. [CrossRef]

27. Dijkmans, P.A.; Juffermans, L.J.M.; Musters, R.J.P.; van Wamel, A.; Cate, F.J.T.; van Gilst, W.; Visser, C.A.; de Jong, N.; Kamp, O. Microbubbles and ultrasound: From diagnosis to therapy. Eur. J. Echocardiogr. 2004, 5, 245-256. [CrossRef]

28. Stride, E.P.; Coussios, C.C. Cavitation and contrast: The use of bubbles in ultrasound imaging and therapy. Proc. Inst. Mech. Eng. Part H J. Eng. Med. 2010, 224, 171-191. [CrossRef]

29. Stride, E.; Segers, T.; Lajoinie, G.; Cherkaoui, S.; Bettinger, T.; Versluis, M.; Borden, M. Microbubble Agents: New Directions. Ultrasound Med. Biol. 2020, 46, 1326-1343. [CrossRef]

30. Stride, E.; Saffari, N. Microbubble ultrasound contrast agents: A review. Proc. Inst. Mech. Eng. Part H J. Eng. Med. 2003, 217, 429-447. [CrossRef]

31. Versluis, M.; Stride, E.; Lajoinie, G.; Dollet, B.; Segers, T. Ultrasound Contrast Agent Modeling: A Review. Ultrasound Med. Biol. 2020, 46, 2117-2144. [CrossRef]

32. Miller, D.L.; Averkiou, M.A.; Brayman, A.A.; Everbach, E.C.; Holland, C.K.; Wible, J.H.; Wu, J. Bioeffects Considerations for Diagnostic Ultrasound Contrast Agents. J. Ultrasound Med. 2008, 27, 611-632. [CrossRef] [PubMed]

33. Yildirim, A.; Blum, N.T.; Goodwin, A.P. Colloids, nanoparticles, and materials for imaging, delivery, ablation, and theranostics by focused ultrasound (FUS). Theranostics 2019, 9, 2572-2594. [CrossRef] 
34. Roovers, S.; Segers, T.; Lajoinie, G.; Deprez, J.; Versluis, M.; de Smedt, S.C.S.C.; Lentacker, I. The role of ultrasound-driven microbubble dynamics in drug delivery: From microbubble fundamentals to clinical translation. Langmuir 2019, 35, 10173-10191. [CrossRef]

35. Segers, T.; Versluis, M.; Lohse, D. Microbubbles for Medical Applications; Royal Society of Chemistry: London, UK, 2015 ; pp. 81-101.

36. Bulte, C.S.E.; Slikkerveer, J.; Meijer, R.I.; Gort, D.; Kamp, O.; Loer, S.A.; de Marchi, S.F.; Vogel, R.; Boer, C.; Bouwman, R.A. Contrast-enhanced ultrasound for myocardial perfusion imaging. Anesth. Analg. 2012, 114, 938-945. [CrossRef] [PubMed]

37. Pathan, F.; Marwick, T.H. Myocardial Perfusion Imaging Using Contrast Echocardiography. Prog. Cardiovasc. Dis. 2015, 57, 632-643. [CrossRef] [PubMed]

38. Durot, I.; Wilson, S.R.; Willmann, J.K. Contrast-enhanced ultrasound of malignant liver lesions. Abdom. Radiol. 2018, 43, 819-847. [CrossRef]

39. Lee, J.; Jeong, W.K.; Lim, H.K.; Kim, A.Y. Focal nodular hyperplasia of the liver: Contrast-enhanced ultrasonographic features with sonazoid. J. Ultrasound Med. 2018, 37, 1473-1480. [CrossRef]

40. Bertolotto, M.; Bucci, S.; Valentino, M.; Currò, F.; Sachs, C.; Cova, M.A. Contrast-enhanced ultrasound for characterizing renal masses. Eur. J. Radiol. 2018, 105, 41-48. [CrossRef]

41. Shirinifard, A.; Thiagarajan, S.; Johnson, M.D.; Calabrese, C.; Sablauer, A. Measuring Absolute Blood Perfusion in Mice Using Dynamic Contrast-Enhanced Ultrasound. Ultrasound Med. Biol. 2017, 43, 1628-1638. [CrossRef]

42. Putz, F.J.; Erlmeier, A.; Wiesinger, I.; Verloh, N.; Stroszczynski, C.; Banas, B.; Jung, E.M. Contrast-enhanced ultrasound (CEUS) in renal imaging at an interdisciplinary ultrasound centre: Possibilities of dynamic microvascularisation and perfusion. Clin. Hemorheol. Microcirc. 2017, 66, 293-302. [CrossRef] [PubMed]

43. Frinking, P.; Segers, T.; Luan, Y.; Tranquart, F. Three Decades of Ultrasound Contrast Agents: A Review of the Past, Present and Future Improvements. Ultrasound Med. Biol. 2020, 46, 892-908. [CrossRef] [PubMed]

44. Anselmo, A.C.; Mitragotri, S. Nanoparticles in the clinic: An update. Bioeng. Transl. Med. 2019, 4, e10143. [CrossRef]

45. Lentacker, I.; de Cock, I.; Deckers, R.; de Smedt, S.C.; Moonen, C.T.W. Understanding ultrasound induced sonoporation: Definitions and underlying mechanisms. Adv. Drug Deliv. Rev. 2014, 72, 49-64. [CrossRef] [PubMed]

46. Heath, C.H.; Sorace, A.; Knowles, J.; Rosenthal, E.; Hoyt, K. Microbubble therapy enhances anti-tumor properties of cisplatin and cetuximab in vitro and in vivo. Otolaryngol. Head Neck Surg. 2012, 146, 938-945. [CrossRef] [PubMed]

47. Bae, Y.J.; Yoon, Y.I.; Yoon, T.J.; Lee, H.J. Ultrasound-guided delivery of siRNA and a chemotherapeutic drug by using microbubble complexes: In vitro and in vivo evaluations in a prostate cancer model. Korean J. Radiol. 2016, 17, 497-508. [CrossRef] [PubMed]

48. Qin, Y.-E.; Tang, W.-F.; Xu, Y.; Wan, F.-R.; Chen, A.-H. Ultrasound-Mediated Co-Delivery of miR-34a and sPD-1 Complexed with Microbubbles for Synergistic Cancer Therapy. Cancer Manag. Res. 2020, 12, 2459-2469. [CrossRef] [PubMed]

49. McDannold, N.; Zhang, Y.; Supko, J.G.; Power, C.; Sun, T.; Peng, C.; Vykhodtseva, N.; Golby, A.J.; Reardon, D.A. Acoustic feedback enables safe and reliable carboplatin delivery across the blood-brain barrier with a clinical focused ultrasound system and improves survival in a rat glioma model. Theranostics 2019, 9, 6284-6299. [CrossRef]

50. Li, T.; Hu, Z.; Wang, C.; Yang, J.; Zeng, C.; Fan, R.; Guo, J. PD-L1-targeted microbubbles loaded with docetaxel produce a synergistic effect for the treatment of lung cancer under ultrasound irradiation. Biomater. Sci. 2020, 8, 1418-1430. [CrossRef]

51. Sheng, W.; Xu, H.; Zheng, L.; Zhuang, Y.; Jiao, L.; Zhou, F.; Zhuge, D.; Chi, T.; Zhao, Y.; Lan, L. Intrarenal delivery of bFGF-loaded liposome under guiding of ultrasound-targeted microbubble destruction prevent diabetic nephropathy through inhibition of inflammation. Artif. Cells Nanomed. Biotechnol. 2018, 46, 373-385. [CrossRef]

52. Zhou, L.; Luo, W. Vascular endothelial growth factor-targeted paclitaxel-loaded liposome microbubbles and inhibition of human epidermoid-2 cell proliferation. Head Neck 2014, 36, 1391. [CrossRef] [PubMed]

53. Hirabayashi, F.; Iwanaga, K.; Okinaga, T.; Takahashi, O.; Ariyoshi, W.; Suzuki, R.; Sugii, M.; Maruyama, K.; Tominaga, K.; Nishihara, T. Epidermal growth factor receptor-targeted sonoporation with microbubbles enhances therapeutic efficacy in a squamous cell carcinoma model. PLoS ONE 2017, 12, e0185293. [CrossRef] [PubMed]

54. Xing, L.; Shi, Q.; Zheng, K.; Shen, M.; Ma, J.; Li, F.; Liu, Y.; Lin, L.; Tu, W.; Duan, Y.; et al. Ultrasound-mediated microbubble destruction (UMMD) Facilitates the delivery of CA19-9 targeted and paclitaxel loaded mPEG-PLGA-PLL nanoparticles in pancreatic cancer. Theranostics 2016, 6, 1573-1587. [CrossRef] [PubMed]

55. Zhou, Y.; Gu, H.; Xu, Y.; Li, F.; Kuang, S.; Wang, Z.; Zhou, X.; Ma, H.; Li, P.; Zheng, Y.; et al. Targeted antiangiogenesis gene therapy using targeted cationic microbubbles conjugated with CD105 antibody compared with untargeted cationic and neutral microbubbles. Theranostics 2015, 5, 399-417. [CrossRef]

56. Sun, J.; Yin, M.; Zhu, S.; Liu, L.; Zhu, Y.; Wang, Z.; Xu, R.X.; Chang, S. Ultrasound-mediated destruction of oxygen and paclitaxel loaded lipid microbubbles for combination therapy in hypoxic ovarian cancer cells. Ultrason. Sonochem. 2016, 28, 319-326. [CrossRef]

57. Escoffre, J.M.; Mannaris, C.; Geers, B.; Novell, A.; Lentacker, I.; Averkiou, M.; Bouakaz, A. Doxorubicin liposome-loaded microbubbles for contrast imaging and ultrasound-triggered drug delivery. IEEE Trans. Ultrason. Ferroelectr. Freq. Control 2013, 60, 78-87. [CrossRef]

58. Chen, Y.-C.; Chiang, C.-F.; Wu, S.-K.; Chen, L.-F.; Hsieh, W.-Y.; Lin, W.-L. Targeting microbubbles-carrying TGF $\beta 1$ inhibitor combined with ultrasound sonication induce BBB/BTB disruption to enhance nanomedicine treatment for brain tumors. $J$. Control. Release 2015, 211, 53-62. [CrossRef] 
59. Kooiman, K.; Vos, H.J.; Versluis, M.; de Jong, N. Acoustic behavior of microbubbles and implications for drug delivery. Adv. Drug Deliv. Rev. 2014, 72, 28-48. [CrossRef]

60. Kooiman, K.; Roovers, S.; Langeveld, S.A.G.; Kleven, R.T.; Dewitte, H.; O'reilly, M.A.; Escoffre, J.-M.; Bouakaz, A.; Verweij, M.D.; Hynynen, K.; et al. Ultrasound-responsive cavitation nuclei for therapy and drug delivery. Ultrasound Med. Biol. 2020, 46, 1296-1325. [CrossRef]

61. Snipstad, S.; Sulheim, E.; Davies, C.D.; Moonen, C.; Storm, G.; Kiessling, F.; Schmid, R.; Lammers, T. Sonopermeation to improve drug delivery to tumors: From fundamental understanding to clinical translation. Expert Opin. Drug Deliv. 2018, 15, 1249-1261. [CrossRef]

62. Qin, J.; Wang, T.Y.; Willmann, J.K. Sonoporation: Applications for cancer therapy. Adv. Exp. Med. Biol. 2016, 880, 263-291. [CrossRef] [PubMed]

63. Alonso, A. Ultrasound-induced blood-brain barrier opening for drug delivery. In Frontiers of Neurology and Neuroscience; S. Karger AG: Basel, Switzerland, 2014; pp. 106-115. [CrossRef]

64. Deprez, J.; Lajoinie, G.; Engelen, Y.; de Smedt, S.C.; Lentacker, I. Opening doors with ultrasound and microbubbles: Beating biological barriers to promote drug delivery. Adv. Drug Deliv. Rev. 2021, 172,9-36. [CrossRef] [PubMed]

65. Cool, S.K.; Geers, B.; Roels, S.; Stremersch, S.; Vanderperren, K.; Saunders, J.H.; de Smedt, S.C.; Demeester, J.; Sanders, N.N. Coupling of drug containing liposomes to microbubbles improves ultrasound triggered drug delivery in mice. J. Control. Release 2013, 172, 885-893. [CrossRef] [PubMed]

66. Roovers, S.; Lajoinie, G.; de Cock, I.; Brans, T.; Dewitte, H.; Braeckmans, K.; Versuis, M.; de Smedt, S.C.; Lentacker, I. Sonoprinting of nanoparticle-loaded microbubbles: Unraveling the multi-timescale mechanism. Biomaterials 2019, 217, 119250. [CrossRef]

67. Roovers, S.; Deprez, J.; Priwitaningrum, D.; Lajoinie, G.; Rivron, N.; Declercq, H.; de Wever, O.; Stride, E.; le Gac, S.; Versluis, M.; et al. Sonoprinting liposomes on tumor spheroids by microbubbles and ultrasound. J. Control. Release 2019, 316, 79-92. [CrossRef]

68. Snipstad, S.; Berg, S.; Mørch, Ý.; Bjørkøy, A.; Sulheim, E.; Hansen, R.; Grimstad, I.; van Wamel, A.; Maaland, A.F.; Torp, S.H.; et al. Ultrasound Improves the Delivery and Therapeutic Effect of Nanoparticle-Stabilized Microbubbles in Breast Cancer Xenografts. Ultrasound Med. Biol. 2017, 43, 2651-2669. [CrossRef]

69. Suzuki, R.; Klibanov, A.L. Co-administration of microbubbles and drugs in ultrasound-assisted drug delivery: Comparison with drug-carrying particles. Adv. Exp. Med. Biol. 2016, 880, 205-220. [CrossRef]

70. de Cock, I.; Lajoinie, G.; Versluis, M.; de Smedt, S.C.; Lentacker, I. Sonoprinting and the importance of microbubble loading for the ultrasound mediated cellular delivery of nanoparticles. Biomaterials 2016, 83, 294-307. [CrossRef]

71. Liu, H.; Huang, C.; Chen, S.; Zheng, Q.; Ye, Y.; Ye, Z.; Lv, G. Value of contrast-enhanced ultrasound for detection of synovial vascularity in experimental rheumatoid arthritis: An exploratory study. J. Int. Med. Res. 2019, 47, 5740-5751. [CrossRef]

72. Fiocco, U.; Stramare, R.; Martini, V.; Coran, A.; Caso, F.; Costa, L.; Felicetti, M.; Rizzo, G.; Tonietto, M.; Scanu, A.; et al. Quantitative imaging by pixel-based contrast-enhanced ultrasound reveals a linear relationship between synovial vascular perfusion and the recruitment of pathogenic IL-17A-F+ IL-23 ${ }^{+} \mathrm{CD}_{161}{ }^{+} \mathrm{CD} 4^{+} \mathrm{T}$ helper cells in psoriatic arthritis joints. Clin. Rheumatol. 2017, 36, 391-399. [CrossRef]

73. De Vries, B.A.; Breda, S.J.; Meuffels, D.E.; Hanff, D.F.; Hunink, M.G.M.; Krestin, G.P.; Oei, E.H.G. Diagnostic accuracy of grayscale, power Doppler and contrast-enhanced ultrasound compared with contrast-enhanced MRI in the visualization of synovitis in knee osteoarthritis. Eur. J. Radiol. 2020, 133, 109392. [CrossRef] [PubMed]

74. Dewitte, H.; Vanderperren, K.; Haers, H.; Stock, E.; Duchateau, L.; Hesta, M.; Saunders, J.H.; de Smedt, S.C.; Lentacker, I. Theranostic mRNA-loaded microbubbles in the lymphatics of dogs: Implications for drug delivery. Theranostics 2015, 5, 97-109. [CrossRef] [PubMed]

75. Wang, S.; Samiotaki, G.; Olumolade, O.; Feshitan, J.A.; Konofagou, E.E. Microbubble Type and Distribution Dependence of Focused Ultrasound Induced Blood Brain Barrier Opening. Ultrasound Med. Biol. 2014, 40, 130-137. [CrossRef] [PubMed]

76. Hirohata, S.; Sakakibara, J. Angioneogenesis as a possible elusive triggering factor in rheumatoid arthritis. Lancet 1999, 353, 1331. [CrossRef]

77. Clavel, G.; Valvason, C.; Yamaoka, K.; Lemeiter, D.; Laroche, L.; Boissier, M.C.; Bessis, N. Relationship between angiogenesis and inflammation in experimental arthritis. Eur. Cytokine Netw. 2006, 17, 202-210. [CrossRef]

78. Brand, D.D.; Latham, K.A.; Rosloniec, E.F. Collagen-induced arthritis. Nat. Protoc. 2007, 2, 1269-1275. [CrossRef]

79. Asquith, D.L.; Miller, A.M.; McInnes, I.B.; Liew, F.Y. Animal models of rheumatoid arthritis. Eur. J. Immunol. 2009, 39, 2040-2044. [CrossRef]

80. Cambré, I.; Gaublomme, D.; Burssens, A.; Jacques, P.; Schryvers, N.; de Muynck, A.; Meuris, L.; Lambrecht, S.; Carter, S.; de Bleser, P.; et al. Mechanical strain determines the site-specific localization of inflammation and tissue damage in arthritis. Nat. Commun. 2018, 9, 4613. [CrossRef]

81. Raatz, Y.; Ibrahim, S.; Feldmann, M.; Paleolog, E.M. Gene expression profiling and functional analysis of angiogenic markers in murine collagen-induced arthritis. Arthritis Res. Ther. 2012, 14, R169. [CrossRef]

82. Li, Y.; Yang, B.; Bai, J.Y.; Xia, S.; Mao, M.; Li, X.; Li, N.; Chen, L. The roles of synovial hyperplasia, angiogenesis and osteoclastogenesis in the protective effect of apigenin on collagen-induced arthritis. Int. Immunopharmacol. 2019, 73, 362-369. [CrossRef] 
83. Koch, A.E. Angiogenesis as a target in rheumatoid arthritis. In Annals of the Rheumatic Diseases; BMJ Publishing Group: London, UK, 2003; pp. 60-67. [CrossRef]

84. Negishi, H.; Ide, M.A.; Yoda, F.; Shiozawa, M.; Hanyuda, J.; Lu, T.; Kasama, K.; Kobayashi, Y. Collagen-Induced Arthritis Expression and Regulation of Murine Vascular Endothelial Growth Factor. J. Immunol. Ref. 2021, 164, 5922-5927. [CrossRef]

85. Delalande, A.; Bouakaz, A.; Renault, G.; Tabareau, F.; Kotopoulis, S.; Midoux, P.; Arbeille, B.; Uzbekov, R.; Chakravarti, S.; Postema, M.; et al. Ultrasound and microbubble-assisted gene delivery in Achilles tendons: Long lasting gene expression and restoration of fibromodulin KO phenotype. J. Control. Release 2011, 156, 223-230. [CrossRef] [PubMed]

86. De Chermont, Q.L.M.; Chanéac, C.; Seguin, J.; Pellé, F.; Maîtrejean, S.; Jolivet, J.P.; Gourier, D.; Bessodes, M.; Scherman, D. Nanoprobes with near-infrared persistent luminescence for in vivo imaging. Proc. Natl. Acad. Sci. USA 2007, 104, 9266-9271. [CrossRef] [PubMed]

87. Chen, J.; Corbin, I.R.; Li, H.; Cao, W.; Glickson, J.D.; Zheng, G. Ligand Conjugated Low-Density Lipoprotein Nanoparticles for Enhanced Optical Cancer Imaging in vivo. J. Am. Chem. Soc. 2007, 129, 5798-5799. [CrossRef] [PubMed]

88. Lentacker, I.; Geers, B.; Demeester, J.; de Smedt, S.C.; Sanders, N.N. Design and evaluation of doxorubicin-containing microbubbles for ultrasound-triggered doxorubicin delivery: Cytotoxicity and mechanisms involved. Mol. Ther. 2010, 18, 101-108. [CrossRef] [PubMed]

89. Suk, J.S.; Xu, Q.; Kim, N.; Hanes, J.; Ensign, L.M. PEGylation as a strategy for improving nanoparticle-based drug and gene delivery. Adv. Drug Deliv. Rev. 2016, 99, 28-51. [CrossRef]

90. Ren, H.; He, Y.; Liang, J.; Cheng, Z.; Zhang, M.; Zhu, Y.; Hong, C.; Qin, J.; Xu, X.; Wang, J. Role of Liposome Size, Surface Charge, and PEGylation on Rheumatoid Arthritis Targeting Therapy. ACS Appl. Mater. Interfaces 2019, 11, 20304-20315. [CrossRef]

91. Gawne, P.J.; Clarke, F.; Turjeman, K.; Cope, A.P.; Long, N.J.; Barenholz, Y.; Terry, S.Y.A.; de Rosales, R.T.M. PET Imaging of Liposomal Glucocorticoids using 89 Zr-oxine: Theranostic Applications in Inflammatory Arthritis. Theranostics 2020, 10, 3867-3879. [CrossRef]

92. Metselaar, J.M.; Wauben, M.H.M.; Wagenaar-Hilbers, J.P.A.; Boerman, O.C.; Storm, G. Complete remission of experimental arthritis by joint targeting of glucocorticoids with long-circulating liposomes. Arthritis Rheum. 2003, 48, 2059-2066. [CrossRef]

93. Komano, Y.; Yagi, N.; Onoue, I.; Kaneko, K.; Miyasaka, N.; Nanki, T. Arthritic Joint-Targeting Small Interfering RNA-Encapsulated Liposome: Implication for Treatment Strategy for Rheumatoid Arthritis. J. Pharmacol. Exp. Ther. 2012, 340, 109-113. [CrossRef]

94. Geers, B.; Lentacker, I.; Sanders, N.N.; Demeester, J.; Meairs, S.; de Smedt, S.C. Self-assembled liposome-loaded microbubbles: The missing link for safe and efficient ultrasound triggered drug-delivery. J. Control. Release 2011, 152, 249-256. [CrossRef] [PubMed]

95. Klibanov, A.L.; Shevchenko, T.I.; Raju, B.I.; Seip, R.; Chin, C.T. Ultrasound-triggered release of materials entrapped in microbubbleliposome constructs: A tool for targeted drug delivery. J. Control. Release 2010, 148, 13-17. [CrossRef] [PubMed]

96. Kolter, T.; Sandhoff, K. Lysosomal degradation of membrane lipids. FEBS Lett. 2010, 584, 1700-1712. [CrossRef]

97. Colino, C.I.; Lanao, J.M.; Gutierrez-Millan, C. Targeting of Hepatic Macrophages by Therapeutic Nanoparticles. Front. Immunol. 2020, 11, 218. [CrossRef]

98. Wisse, E.; Jacobs, F.; Topal, B.; Frederik, P.; de Geest, B. The size of endothelial fenestrae in human liver sinusoids: Implications for hepatocyte-directed gene transfer. Gene Ther. 2008, 15, 1193-1199. [CrossRef]

99. Escoffre, A.; Bouakaz, J.M. Therapeutic Ultrasound (Overview). Adv. Exp. Med. Biol. 2016, 880, 459.

100. Burmester, G.R.; Pope, J.E. Novel treatment strategies in rheumatoid arthritis. Lancet 2017, 389, 2338-2348. [CrossRef]

101. Mignani, S.; Bryszewska, M.; Klajnert-Maculewicz, B.; Zablocka, M.; Majoral, J.P. Advances in combination therapies based on nanoparticles for efficacious cancer treatment: An analytical report. Biomacromolecules 2015, 16, 1-27. [CrossRef] [PubMed]

102. Gaffo, A.; Saag, K.G.; Curtis, J.R. Treatment of rheumatoid arthritis. Am. J. Health Pharm. 2006, 63, 2451-2465. [CrossRef]

103. Kumar, P.; Banik, S. Pharmacotherapy Options in Rheumatoid Arthritis. Clin. Med. Insights Arthritis Musculoskelet. Disord. 2013, 6, S5558. [CrossRef]

104. Stevens, C.R.; Blake, D.R.; Merry, P.; Revell, P.A.; Levick, J.R. A comparative study by morphometry of the microvasculature in normal and rheumatoid synovium. Arthritis Rheum. 1991, 34, 1508-1513. [CrossRef]

105. Tsai, A.G.; Friesenecker, B.; Intaglietta, M. Capillary flow impairment and functional capillary density. Int. J. Microcirc. Clin. Exp. 1995, 15, 238-243. [CrossRef] [PubMed]

106. Nolte, D.; Zeintl, H.; Steinbauer, M.; Pickelmann, S.; Messmer, K. Functional capillary density: An indicator of tissue perfusion? Int. J. Microcirc. Exp. 1995, 15, 244-249. [CrossRef]

107. Zhu, B.; Wang, L.; Huang, J.; Xiang, X.; Tang, Y.; Cheng, C.; Yan, F.; Ma, L.; Qiu, L. Ultrasound-triggered perfluorocarbon-derived nanobombs for targeted therapies of rheumatoid arthritis. J. Mater. Chem. B 2019, 7, 4581-4591. [CrossRef]

108. Sheeran, P.S.; Luois, S.; Dayton, P.A.; Matsunaga, T.O. Formulation and acoustic studies of a new phase-shift agent for diagnostic and therapeutic ultrasound. Langmuir 2011, 27, 10412-10420. [CrossRef] [PubMed]

109. Xiang, X.; Tang, Y.; Leng, Q.; Zhang, L.; Qiu, L. Targeted gene delivery to the synovial pannus in antigen-induced arthritis by ultrasound-targeted microbubble destruction in vivo. Ultrasonics 2016, 65, 304-314. [CrossRef]

110. Ferrara, K.W.; Borden, M.A.; Zhang, H. Lipid-shelled vehicles: Engineering for ultrasound molecular imaging and drug delivery. Acc. Chem. Res. 2009, 42, 881-892. [CrossRef]

111. Sirsi, S.; Feshitan, J.; Kwan, J.; Homma, S.; Borden, M. Effect of microbubble size on fundamental mode high frequency ultrasound imaging in mice. Ultrasound Med. Biol. 2010, 36, 935-948. [CrossRef] [PubMed] 
112. Ergen, C.; Heymann, F.; al Rawashdeh, W.; Gremse, F.; Bartneck, M.; Panzer, U.; Pola, R.; Pechar, M.; Storm, G.; Mohr, N.; et al. Targeting distinct myeloid cell populations in vivo using polymers, liposomes and microbubbles. Biomaterials 2017, 114, 106-120. [CrossRef]

113. Iijima, H.; Moriyasu, F.; Miyahara, T.; Yanagisawa, K. Ultrasound contrast agent, Levovist microbubbles are phagocytosed by Kupffer cells-in vitro and in vivo studies. Hepatol. Res. 2006, 35, 235-237. [CrossRef]

114. Yanagisawa, K.; Moriyasu, F.; Miyahara, T.; Yuki, M.; Iijima, H. Phagocytosis of ultrasound contrast agent microbubbles by Kupffer cells. Ultrasound Med. Biol. 2007, 33, 318-325. [CrossRef] [PubMed]

115. Kindberg, G.M.; Tolleshaug, H.; Roos, N.; Skotland, T. Hepatic clearance of Sonazoid perfluorobutane microbubbles by Kupffer cells does not reduce the ability of liver to phagocytose or degrade albumin microspheres. Cell Tissue Res. 2003, 312, 49-54. [CrossRef] [PubMed]

116. Barrefelt, Å.; Saghafian, M.; Kuiper, R.; Ye, F.; Egri, G.; Klickermann, M.; Brismar, T.B.; Aspelin, P.; Muhammed, M.; Dähne, L.; et al. Biodistribution, kinetics, and biological fate of SPION microbubbles in the rat. Int. J. Nanomed. 2013, 8, 3241-3254. [CrossRef]

117. Braet, F.; Wisse, E. Structural and functional aspects of liver sinusoidal endothelial cell fenestrae: A review. Comp. Hepatol. 2002, 1, 1. [CrossRef]

118. Zapotoczny, B.; Szafranska, K.; Kus, E.; Braet, F.; Wisse, E.; Chlopicki, S.; Szymonski, M. Tracking Fenestrae Dynamics in Live Murine Liver Sinusoidal Endothelial Cells. Hepatology 2019, 69, 876-888. [CrossRef] [PubMed]

119. Nguyen-Lefebvre, A.T.; Horuzsko, A. Kupffer Cell Metabolism and Function. In J. Enzymol. Metab.; $2015 ; 1$, p. 101.

120. Schneider, M.; Broillet, A.; Tardy, I.; Pochon, S.; Bussat, P.; Bettinger, T.; Helbert, A.; Costa, M.; Tranquart, F. Use of Intravital Microscopy to Study the Microvascular Behavior of Microbubble-Based Ultrasound Contrast Agents. Microcirculation 2012, 19, 245-259. [CrossRef]

121. Bioley, G.; Bussat, P.; Lassus, A.; Schneider, M.; Terrettaz, J.; Corthésy, B. The phagocytosis of gas-filled microbubbles by human and murine antigen-presenting cells. Biomaterials 2012, 33, 333-342. [CrossRef]

122. Fadok, V.A.; Bratton, D.L.; Frasch, S.C.; Warner, M.L.; Henson, P.M. The role of phosphatidylserine in recognition of apoptotic cells by phagocytes. Cell Death Differ. 1998, 5, 551-562. [CrossRef]

123. Segawa, K.; Nagata, S. An Apoptotic “Eat Me" Signal: Phosphatidylserine Exposure. Trends Cell Biol. 2015, 25, 639-650. [CrossRef]

124. Ryan, S.M.; Mantovani, G.; Wang, X.; Haddleton, D.M.; Brayden, D.J. Advances in PEGylation of important biotech molecules: Delivery aspects. Expert Opin. Drug Deliv. 2008, 5, 371-383. [CrossRef] [PubMed]

125. Chen, C.C.; Borden, M.A. The role of poly(ethylene glycol) brush architecture in complement activation on targeted microbubble surfaces. Biomaterials 2011, 32, 6579-6587. [CrossRef] [PubMed]

126. Maruyama, H.; Matsutani, S.; Saisho, H.; Mine, Y.; Yuki, H.; Miyata, K. Different behaviors of microbubbles in the liver: Time-related quantitative analysis of two ultrasound contrast agents, Levovist ${ }^{\circledR}$ and Definity ${ }^{\circledR}$. Ultrasound Med. Biol. 2004, 30, 1035-1040. [CrossRef]

127. Sercombe, L.; Veerati, T.; Moheimani, F.; Wu, S.Y.; Sood, A.K.; Hua, S. Advances and challenges of liposome assisted drug delivery. Front. Pharmacol. 2015, 6, 286. [CrossRef]

128. Guillot, A.; Tacke, F. Liver Macrophages: Old Dogmas and New Insights. Hepatol. Commun. 2019, 3, 730-743. [CrossRef]

129. Honari, A.; Merillat, D.A.; Bellary, A.; Ghaderi, M.; Sirsi, S.R. Improving Release of Liposome-Encapsulated Drugs with Focused Ultrasound and Vaporizable Droplet-Liposome Nanoclusters. Pharmaceutics 2021, 13, 609. [CrossRef]

130. Liu, W.W.; Liu, S.W.; Liou, Y.R.; Wu, Y.H.; Yang, Y.C.; Wang, C.R.C.; Li, P.C. Nanodroplet-Vaporization-Assisted Sonoporation for Highly Effective Delivery of Photothermal Treatment. Sci. Rep. 2016, 6, 24753. [CrossRef]

131. Ho, J.Y.; Yeh, C.K. Theranostic performance of acoustic nanodroplet vaporization-generated bubbles in tumor intertissue. Theranostics 2017, 7, 1477-1488. [CrossRef]

132. Yan, F.; Li, L.; Deng, Z.; Jin, Q.; Chen, J.; Yang, W.; Yeh, C.K.; Wu, J.; Shandas, R.; Liu, X.; et al. Paclitaxel-liposome-microbubble complexes as ultrasound-triggered therapeutic drug delivery carriers. J. Control. Release 2013, 166, 246-255. [CrossRef] [PubMed]

133. Hynynen, K. Ultrasound for drug and gene delivery to the brain. Adv. Drug Deliv. Rev. 2008, 60, 1209-1217. [CrossRef] [PubMed]

134. Sheikov, N.; McDannold, N.; Sharma, S.; Hynynen, K. Effect of Focused Ultrasound Applied with an Ultrasound Contrast Agent on the Tight Junctional Integrity of the Brain Microvascular Endothelium. Ultrasound Med. Biol. 2008, 34, 1093-1104. [CrossRef] [PubMed]

135. Curley, C.T.; Sheybani, N.D.; Bullock, T.N.; Price, R.J. Focused ultrasound immunotherapy for central nervous system pathologies: Challenges and opportunities. Theranostics 2017, 7, 3608-3623. [CrossRef] [PubMed]

136. Wang, T.-Y.Y.; Choe, J.W.; Pu, K.; Devulapally, R.; Bachawal, S.; Machtaler, S.; Chowdhury, S.M.; Luong, R.; Tian, L.; KhuriYakub, B.; et al. Ultrasound-guided delivery ofmicroRNA loaded nanoparticles into cancer. J. Control. Release 2015, 203, 99-108. [CrossRef] [PubMed]

137. Ting, C.Y.; Fan, C.H.; Liu, H.L.; Huang, C.Y.; Hsieh, H.Y.; Yen, T.C.; Wei, K.C.; Yeh, C.K. Concurrent blood-brain barrier opening and local drug delivery using drug-carrying microbubbles and focused ultrasound for brain glioma treatment. Biomaterials 2012, 33, 704-712. [CrossRef] [PubMed]

138. Kang, J.; Wu, X.; Wang, Z.; Ran, H.; Xu, C.; Wu, J.; Wang, Z.; Zhang, Y. Antitumor effect of docetaxel-loaded lipid microbubbles combined with ultrasound-targeted microbubble activation on VX2 rabbit liver tumors. J. Ultrasound Med. 2010, 29, 61-70. [CrossRef] [PubMed] 
139. Lammertink, B.H.A.; Bos, C.; Deckers, R.; Storm, G.; Moonen, C.T.W.; Escoffre, J.M. Sonochemotherapy: From bench to bedside. Front. Pharmacol. 2015, 6, 138. [CrossRef]

140. Avnir, Y.; Ulmansky, R.; Wasserman, V.; Even-Chen, S.; Broyer, M.; Barenholz, Y.; Naparstek, Y. Amphipathic weak acid glucocorticoid prodrugs remote-loaded into sterically stabilized nanoliposomes evaluated in arthritic rats and in a Beagle dog: A novel approach to treating autoimmune arthritis. Arthritis Rheum. 2008, 58, 119-129. [CrossRef]

141. Avnir, Y.; Turjeman, K.; Tulchinsky, D.; Sigal, A.; Kizelsztein, P.; Tzemach, D.; Gabizon, A.; Barenholz, Y. Fabrication principles and their contribution to the superior in vivo therapeutic efficacy of nano-liposomes remote loaded with glucocorticoids. PLoS ONE 2011, 6, e25721. [CrossRef]

142. De Cock, I.; Zagato, E.; Braeckmans, K.; Luan, Y.; de Jong, N.; de Smedt, S.C.; Lentacker, I. Ultrasound and microbubble mediated drug delivery: Acoustic pressure as determinant for uptake via membrane pores or endocytosis. J. Control. Release 2015, 197, 20-28. [CrossRef]

143. Dewitte, H.; van Lint, S.; Heirman, C.; Thielemans, K.; de Smedt, S.C.; Breckpot, K.; Lentacker, I. The potential of antigen and TriMix sonoporation using mRNA-loaded microbubbles for ultrasound-triggered cancer immunotherapy. J. Control. Release 2014, 194, 28-36. [CrossRef] 